\title{
Effect of Processing Parameters and Shape of Blade on the Solidification of Single-Crystal CMSX-4 Ni-Based Superalloy
}

\begin{abstract}
DARIUSZ SZELIGA
The effect of mold withdrawal velocity, heater and pouring temperatures and the thickness of blade root on the solidification parameters and shape of the liquidus isotherm as well as microstructure of single-crystal CMSX-4 nickel-based superalloy, manufactured by the Bridgman method, has been analyzed in the article. The temperature gradient $G$, solidification rate $v$ and location of the liquidus isotherm were determined in relation to the radiation baffle on the basis of temperature measurements conducted in nine test points along the height of castings $(140 \mathrm{~mm})$ with different thicknesses of root $(27,15$ and $7 \mathrm{~mm})$ and withdrawal velocities of 3 and $5 \mathrm{~mm} / \mathrm{min}$. The increase of root thickness, relative to the airfoil, resulted in the rise of inhomogeneity of solidification parameters as well as the primary dendrite arm spacing and unsteady state solidification along the whole blade height. However, in the case of blade with constant thickness, the steady-state solidification was created at the distance of 65 to $130 \mathrm{~mm}$ from its base. The increase of mold withdrawal velocity caused the decrease of temperature gradient. However, the solidification rate was different from the mold withdrawal velocity, especially in the root and middle part of the airfoil. The increase of heater temperature resulted in a rise of temperature gradient and reduction of the curvature of the liquidus isotherm, whereas the pouring temperature did not affect the solidification parameters in the blade. Particularly unfavorable conditions of the solidification process could occur in the middle part of the airfoil and root because of the lowest value of $G / v$ and the largest primary dendrite arm spacing.
\end{abstract}

https://doi.org/10.1007/s11663-018-1347-z

(C) The Author(s) 2018

\section{INTRODUCTION}

THE development of turbine aircraft engines is focused on the improvement of their efficiency, which mainly depends on the temperature of exhaust gases before the turbine. Reed ${ }^{[1]}$ reported that the maximum temperature of gases at the turbine inlet depended on the properties of materials applied in the engine hot section elements, mainly those of blades of high-pressure turbines.

Kubiak et al. ${ }^{[2]}$ described Bridgman and liquid metal cooling (LMC) methods for the directional solidification of single-crystal turbine blades made of nickel superalloy, applied in the aircraft engines and industrial gas

DARIUSZ SZELIGA is with the Department of Materials Science, Faculty of Mechanical Engineering and Aeronautics, Rzeszow University of Technology, 12, Powstancow Warszawy Str., 35-959 Rzeszow, Poland and also with the Research and Development Laboratory for Aerospace Materials, 4, Żwirki i Wigury Str., 35-036

Rzeszow, Poland. Contact e-mail: dszeliga@prz.edu.pl

Manuscript submitted April 29, 2017.

Article published online July 26, 2018. turbines. The manufacturing process of these castings consists of pouring liquid metal into the preheated ceramic shell mold and its withdrawal at a specially selected velocity from the heating to the cooling area of the furnace. The industrial version of the furnace is equipped with cylinder-shaped heaters and chill rings in most cases. The manufacturing technique and value of the withdrawal velocity of the ceramic shell mold influence the parameters of the solidification process, i.e., the temperature gradient and solidification rates of casting, to a large extent. ${ }^{[3]}$ Cooling the ceramic shell mold with liquid metal (LMC) makes increasing the withdrawal velocity and temperature gradient possible compared with the Bridgman method in which the cooling technique is performed by radiation in vacuum. ${ }^{[4]}$ The temperature gradient, solidification and cooling rates determine the shape of the solid/liquid interface and microstructure of single-crystal castings. ${ }^{[5]}$ An increase of the cooling rate leads to the favorable refinement of primary dendrite arm spacing and the decrease of eutectic islands $\left(\gamma+\gamma^{\prime}\right)$ and $\gamma^{\prime}$ precipitation as well as microsegregation, which result in the reduction of the duration and cost of the heat treatment process. ${ }^{[6]}$ 
Temperature gradient $G$ and solidification rate $v$ affect the formation of defects (freckles, high-angle grain boundaries, stray grains), especially in the case of large single-crystal castings made of nickel superalloy. ${ }^{[7]}$ The lateral growth of dendrites and nucleation of unfavorable grains appear for the values of $G / v=1000$ and $3500{ }^{\circ} \mathrm{C} \mathrm{s} / \mathrm{cm}^{2}$, respectively. ${ }^{[8]}$

The parameters of the solidification process are usually established by performing numerical simulation for casting rods. Szeliga et al. ${ }^{[9]}$ presented the solidification process with fixed parameters values, which started to change slightly above a certain height of rods. Their values for blades changed to a greater extent because of a sudden change of cross section. ${ }^{[10]}$ The solidification process of blades is more complicated and the tendency of defect formation is stronger compared with the rod castings. ${ }^{[11]}$ There is little information in the literature on the temperature distribution and solidification parameters suitable for the application in manufacturing single-crystal turbine blades. $\mathrm{Yu}$ et $a .^{[12]}$ presented the results of temperature distribution measurements performed at different points in single-crystal blades. However, the values of the solidification parameters were not calculated. Li et al. ${ }^{[13]}$ applied the values of recorded temperature for the verification of numerical simulation results. Goldschmidt et al. ${ }^{[14]}$ and Meyer ter Vehn ${ }^{[15]}$ showed the temperature measurements only in the platform. Miller and Pollock ${ }^{[16]}$ examined the temperature distribution and established the values of solidification parameters at three points in tri-crystal castings.

The determination of the actual parameters of the solidification process for blade castings is difficult. It was rarely described in the literature, especially in terms of process description along the height of a single-crystal blade. Therefore, a method for establishing the solidification parameters on the basis of temperature changes was developed during the production of single-crystal blades with the Bridgman method. Those data were used to calculate the temperature gradient, solidification rate and location of the liquidus isotherm relative to the radiation baffle along the height of the blade casting $(140 \mathrm{~mm})$, which was being withdrawn at the velocity of 3 and $5 \mathrm{~mm} / \mathrm{min}$. Different root thicknesses were also taken into account.

\section{METHODOLOGY}

\section{A. Directional Solidification Process}

The directional solidification processes of single-crystal castings were conducted in a VIM 2 E-DS/SC furnace (ALD Vacuum Technologies) in the Research and Development Laboratory for Aerospace Materials, Rzeszow University of Technology. The scheme of the furnace for the production of nickel superalloy single-crystal blades using the Bridgman method is presented in Figure 1.

Three geometric models of single-crystal blade castings were designed to determine the parameters of the solidification process along their height (Figure 2). The dummy blade had a similar geometry and size to the actual blade applied in the aircraft engines. The model

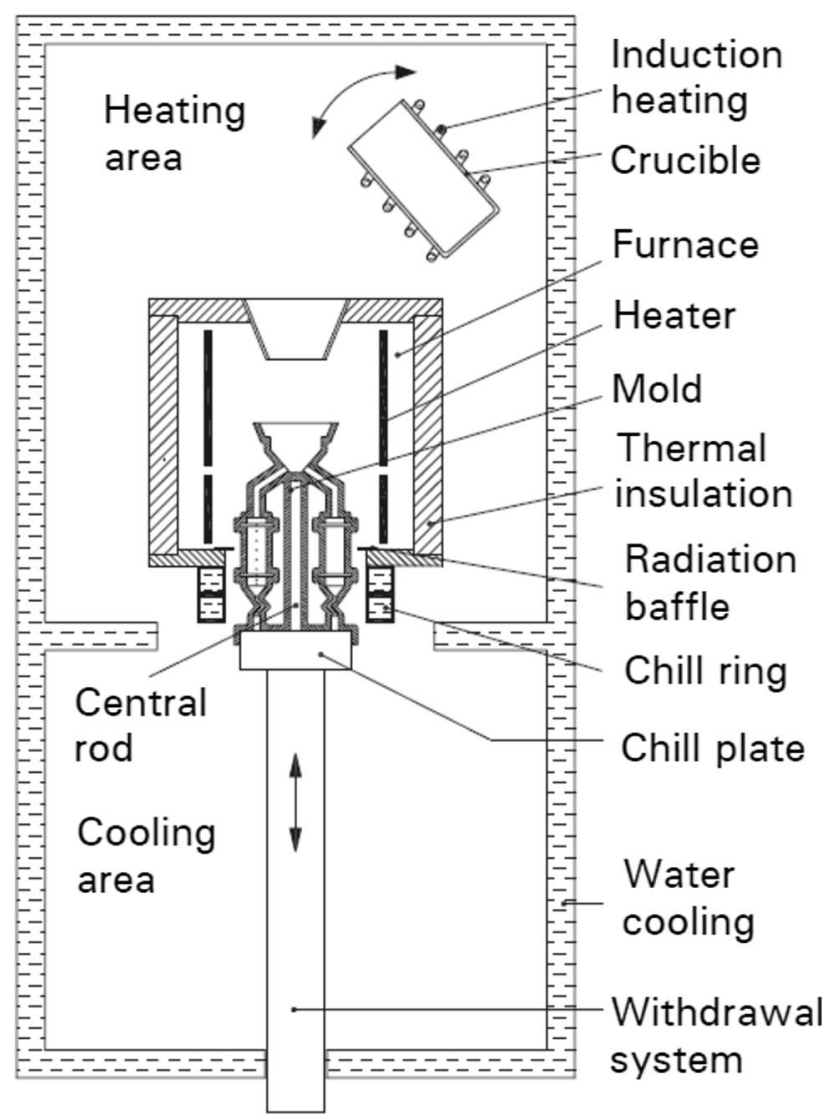

Fig. 1-Scheme of the furnace for production of the nickel superalloy single-crystal blade.

was divided into sectors designated as the continuer, root, bottom platform, airfoil and top platform (Figures 2(a) and (b)). Castings applied in the research differed in terms of root and platform geometry and were designated as blade 1, 2 and 3 (Figures 2(b) through (d)). The root thicknesses were chosen to be 27,15 and $7 \mathrm{~mm}$ for platforms 31, 23 and $7 \mathrm{~mm}$ for blade 1, 2 and 3 , respectively. Temperature test points were specified in the blade casting. The measurements were conducted in nine test points at the distances of 22, 29, 37, 48, 65, 82, 99, 116 and $127 \mathrm{~mm}$ from the casting base (Figure 2(a)). The models of blade castings and elements of model assemblies were used as a basis for the preparation of a wax model. The wax assembly consisted of a central rod, pouring cup, gate, blades (5 pieces), starters and selectors (5 pieces) (Figures 3(a), (c) and (e)). The blade models were located radially in the assembly (Figure 2(a)). It was assumed that larger surface of the airfoil should be oriented parallel to the radius of the wax assembly. The distance between the symmetry axis of the blades and central rod equaled $70 \mathrm{~mm}$. The chill plate was $61 \mathrm{~mm}$ away from the base of the blade.

Layers of the ceramic shell mold were applied on the prepared wax assemblies (Figures 3(b) and (d)). Two molds were created for blade 2 and one for blade 1 and 3 . During the preparation of wax assemblies, ceramic tubes were introduced to provide protection against the direct influence of the liquid alloy. The temperature measurements allowed establishing the actual 


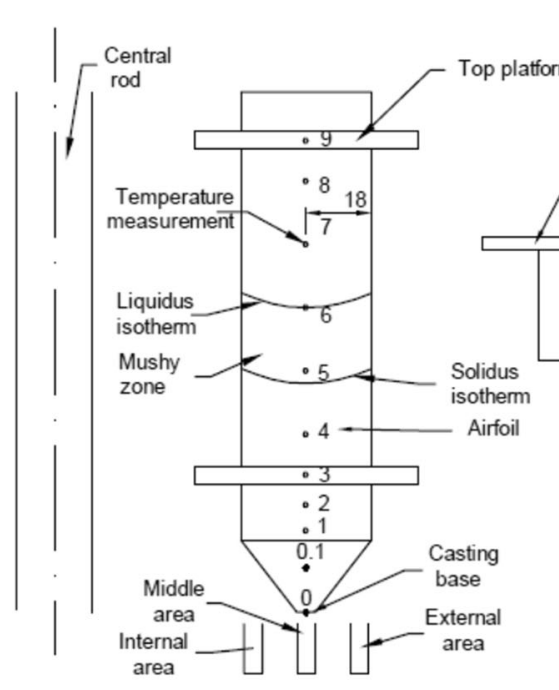

(a)

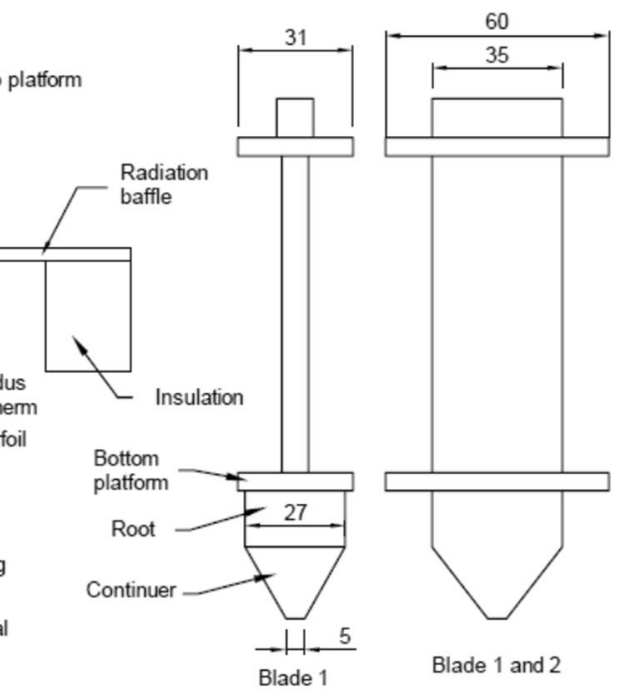

(b)

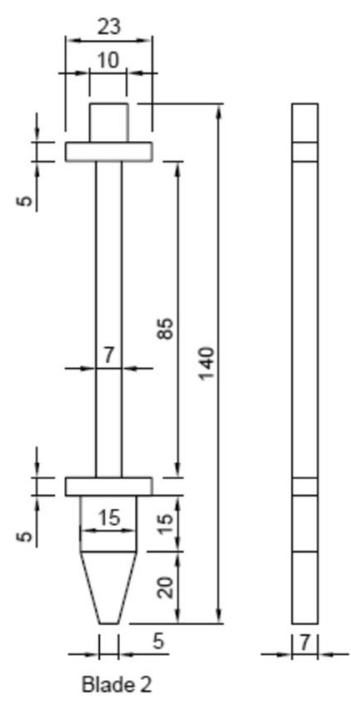

(c)

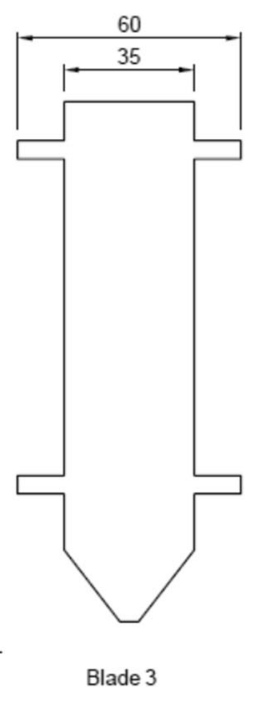

(d)

Fig. 2- Geometric model of blade casting with different thicknesses of the root and platforms ( $b$ through $d$ ) and temperature measurement points $(a)$. Nine test points for temperature measurement located at distances 1-22 mm, 2-29, 3-37, 4-48, 5-65, 6-82, 7-99, 8-116 and 9-127 from the casting base.

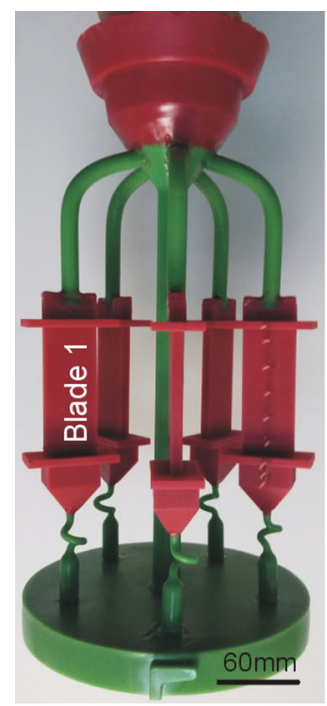

(a)

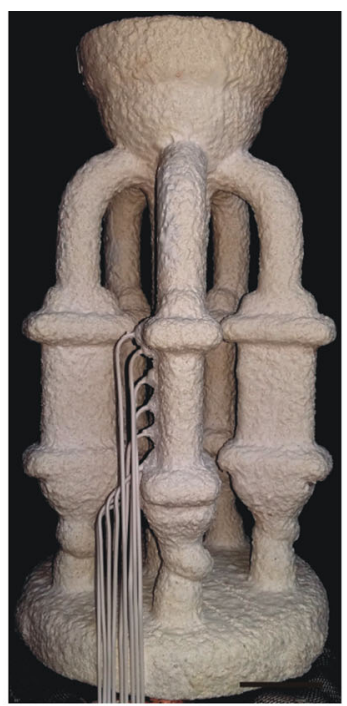

(b)

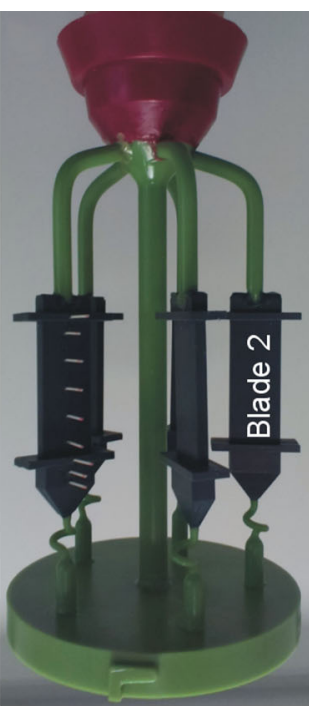

(c)

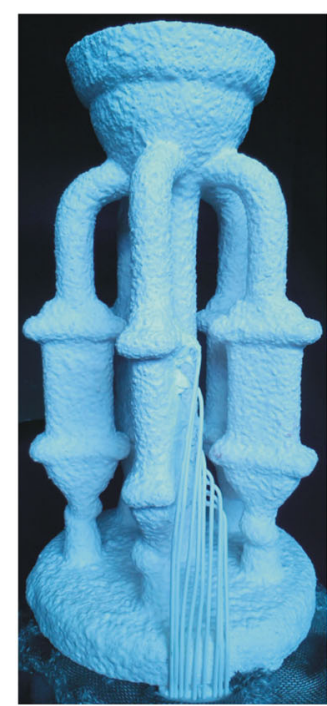

(d)

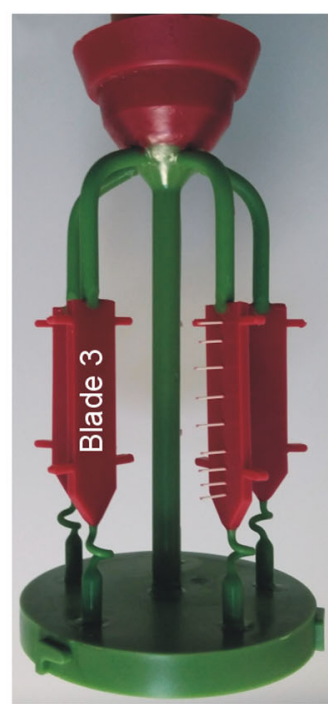

(e)

Fig. 3-Wax models $(a, c, e)$ and ceramic shell molds placed on a chill plate in the furnace $(b, d)$ with mounted thermocouples: (a, b) blade 1; (c, d) blade 2 ; (e) blade 3 .

parameters of the solidification process with type B thermocouples (PtRh6 and PtRh30) with $0.2 \mathrm{~mm}$ diameter. The application of ceramic tubes provided protection of thermocouples outside the mold. In total, 36 thermocouples with $0.5 \mathrm{~m}$ average length were applied in the experiments (Figures 3(b) and (d)).

The ceramic shell mold, located on a chill plate with connected thermocouples, was moved from the cooling to the heating area of the furnace (Figure 1). The castings were manufactured using a $2 \mathrm{~mm}$-thick ringshaped radiation baffle (internal diameter $225 \mathrm{~mm}$ ). The baffle was placed on the lower surface of the thermal insulation of the heating chamber, which was directly located on chill rings. The mold was preheated to
$1793 \mathrm{~K}\left(1520^{\circ} \mathrm{C}\right)$ and then poured with liquid CMSX-4 alloy (Ni, Co-9.6, Cr-6.5, Mo-0.6, W-6.4, Ta-6.5, Ti-1.0, Al-5.6, Re-3, Hf-0.1 wt pct) of the same temperature. Afterwards, each mold was shifted for a distance of $300 \mathrm{~mm}$ at a constant withdrawal velocity of $3 \mathrm{~mm} / \mathrm{min}$ for molds with blades 1,2 and 3 or $5 \mathrm{~mm} / \mathrm{min}$ for mold with blade 2 from the furnace heating to cooling area.

\section{B. Numerical Simulation}

The numerical simulation of the temperature distribution and parameters of the directional solidification process for the castings manufactured by the Bridgman method was executed using ProCAST software. Based 
on the prepared assemblies of models and mold ambience, finite element mesh was defined (Figure 4). Afterwards, an $8 \mathrm{~mm}$-thick layer of the ceramic shell mold was generated on the model assembly (Figure 4(b)). The geometric model of the heating furnace shows the internal surface of two heaters with $300 \mathrm{~mm}$ diameter (Figure 4(c)). The models of the $30 \mathrm{~mm}$-thick insulation layer located on chill rings and $2 \mathrm{~mm}$-thick radiation baffle with $225 \mathrm{~mm}$ internal diameter are also shown in Figure 4(b). The cooling chamber of the furnace consists of internal chill rings and a cooling area with 250 and $600 \mathrm{~mm}$ diameter, respectively (Figure 4(c)). The geometric model was divided into five parts to reduce the time needed to prepare the simulation process.

The directional solidification process was conducted in the furnace under vacuum. Therefore, it was assumed that the heat transfer between the mold surface and its three-dimensional ambience occurs through radiation. The values of the emissivity coefficient for the mold surface $^{[17]}$ as well as the remaining elements of the assembly and the ambience were selected from References 18, 19 (Tables I, II). The density, thermal conductivity, specific heat and fraction solid for the CMSX-4 nickel superalloy were selected based on literature data ${ }^{[20]}$ (Table III). The liquidus and solidus temperature and enthalpy for the alloy were chosen based on the research conducted by Chapman et al. ${ }^{[21]}$ (Table III). The liquidus temperature was assumed to be $1655 \mathrm{~K}\left(1382{ }^{\circ} \mathrm{C}\right)$ and that of solidus $1593 \mathrm{~K}\left(1320^{\circ} \mathrm{C}\right)$. The thermophysical parameters of the ceramic shell mold $^{[22]}$ and insulation as well as radiation baffle ${ }^{[23]}$ are presented in Tables IV and V. The heat transfer coefficients at the interface between the casting mold ${ }^{[9]}$ and chill plate casting ${ }^{[24]}$ assumed in the simulations are presented in Table VI. ${ }^{[9]}$ Numerical simulations were conducted to determine the influence of casting shape and process parameters on parameters of solidification. The withdrawal velocity of the mold, heater and pouring temperatures as well as the blade shape applied during the numerical simulation are presented in Table VII.

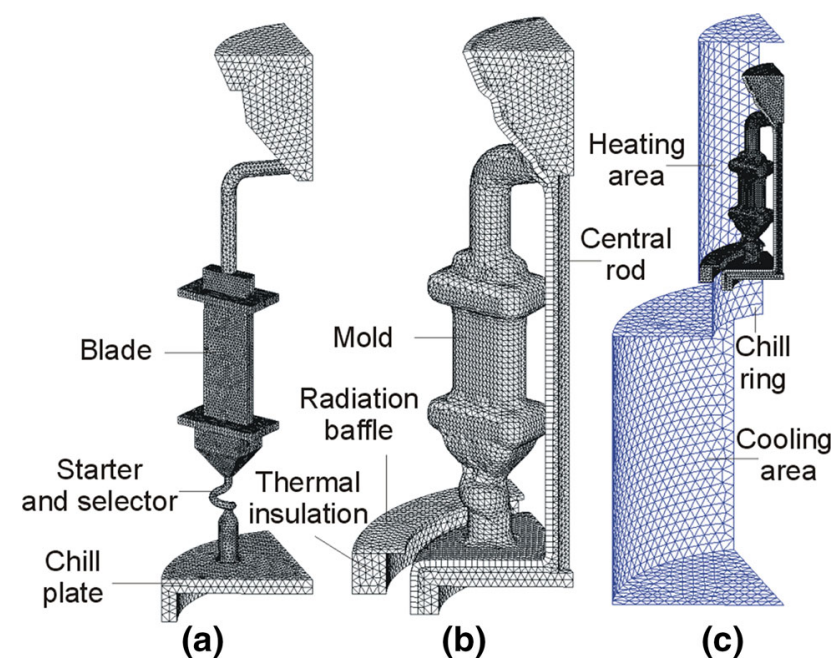

Fig. 4-Finite element mesh of: (a) assembly with blade 1; (b) mold, radiation baffle and thermal insulation; $(c)$ mold ambience (cooling and heating area).
The pouring temperature of the mold for blade 1,2 and 3 was assumed to be $1780 \mathrm{~K}, 1738 \mathrm{~K}$ and $1780 \mathrm{~K}$ $\left(1507^{\circ} \mathrm{C}, 1465{ }^{\circ} \mathrm{C}\right.$ and $1485^{\circ} \mathrm{C}$ ), respectively. It was determined on the basis of the real temperature measurements in the mold cavity (Figure 6).

\section{Microstructure Examination}

The microscopic examination was conducted along the blade height in its internal, external and middle area (Figure 2(a)). The internal and external areas were assumed to be located near the central rood and the furnace heater, respectively (Figure 1). Primary dendrite arm spacing (PDAS) was determined on the cross section at temperature test points (points 1-9) and additionally in the continuer (point 0.1 ) and the casting base (point 0), based on the following equation:

$$
\mathrm{PDAS}=\sqrt{\frac{A}{N}}
$$

where $A$ is the the area of analyzed casting, and $N$ is the quantity of dendrite cores on the surface. The dendritic microstructure was revealed by etching, using reagent with the chemical composition of $33 \mathrm{ml}$ $\mathrm{CH}_{3} \mathrm{COOH}+33 \mathrm{ml} \mathrm{HNO}_{3}+33 \mathrm{ml} \mathrm{H} \mathrm{H}_{2} \mathrm{O}+1 \mathrm{ml} \mathrm{HF}$. The observations of the microstructure were carried out for each cross section on the $4 \times 5 \mathrm{~mm}$ area. The quantity of dendrite cores on the analyzed transverse surface was between 50 and 250 depending on the value of withdrawal velocity and distance from the casting base.

\section{Solidification Parameters}

The experiment was conducted to establish the actual temperature gradient, solidification rate, cooling rate of the casting and location of the liquidus isotherm relative to the radiation baffle along the height of the blade.

Table I. Emissivity of the Surface of the Ceramic Shell Mold Depending on Temperature

\begin{tabular}{lc}
\hline Temperature $(\mathrm{K})$ & Emissivity $^{[17]}$ \\
\hline 400 & 0.76 \\
600 & 0.71 \\
800 & 0.61 \\
1000 & 0.52 \\
1200 & 0.47 \\
1400 & 0.43 \\
\hline
\end{tabular}

Table II. Emissivity of the Surface for Applied Materials

\begin{tabular}{ll}
\hline Material & Emissivity \\
\hline Heater & $0.87^{[19]}$ \\
Insulation & $0.4^{[18]}$ \\
Radiation Baffle & $0.4^{[18]}$ \\
Chill Ring & $0.7^{[18]}$ \\
Cooling Area of Furnace & $0.5^{[18]}$ \\
\hline
\end{tabular}


Table III. Thermophysical Parameters of the CMSX-4 Ni-Based Superalloy in the Function of Temperature

\begin{tabular}{|c|c|c|c|c|c|c|c|}
\hline $\begin{array}{l}\text { Temperature } \\
(\mathrm{K})\end{array}$ & $\begin{array}{l}\text { Enthalpy } \\
(\mathrm{kJ} / \mathrm{kg})^{[21]}\end{array}$ & $\begin{array}{l}\text { Temperature } \\
(\mathrm{K})\end{array}$ & $\begin{array}{l}\text { Thermal Conductivity } \\
\qquad(\mathrm{W} / \mathrm{m} \mathrm{K})^{[20]}\end{array}$ & $\begin{array}{l}\text { Temperature } \\
(\mathrm{K})\end{array}$ & $\begin{array}{l}\text { Density }(\mathrm{kg} / \\
\left.\mathrm{m}^{3}\right)^{[20]}\end{array}$ & $\begin{array}{l}\text { Temperature } \\
(\mathrm{K})\end{array}$ & $\begin{array}{l}\text { Fraction } \\
\text { Solid }^{[20]}\end{array}$ \\
\hline 298 & 0 & 373 & 8.65 & 298 & 8700 & 1593 & 1 \\
\hline 474 & 74 & 573 & 11.6 & 373 & 8665 & 1614 & 0.95 \\
\hline 696 & 173 & 773 & 14.9 & 473 & 8618 & 1620 & 0.9 \\
\hline 843 & 242 & 1173 & 20 & 573 & 8572 & 1628 & 0.8 \\
\hline 1023 & 335 & 1573 & 32 & 673 & 8525 & 1633 & 0.7 \\
\hline 1276 & 481 & 1653 & 25.6 & 773 & 8479 & 1636 & 0.6 \\
\hline 1349 & 528 & 1773 & 25.3 & 873 & 8433 & 1639 & 0.5 \\
\hline 1402 & 566 & 1873 & 25 & 973 & 8387 & 1642 & 0.4 \\
\hline 1474 & 622 & & & 1073 & 8342 & 1647 & 0.2 \\
\hline 1585 & 714 & & & 1173 & 8296 & 1649 & 0.1 \\
\hline 1593 & 722 & & & 1273 & 8251 & 1655 & 0 \\
\hline 1605 & 732 & & & 1373 & 8206 & & \\
\hline 1620 & 762 & & & 1473 & 8161 & & \\
\hline 1629 & 798 & & & 1573 & 8116 & & \\
\hline 1631 & 824 & & & 1593 & 8107 & & \\
\hline 1640 & 861 & & & 1653 & 7754 & & \\
\hline 1649 & 918 & & & 1673 & 7736 & & \\
\hline 1653 & 941 & & & 1773 & 7646 & & \\
\hline 1655 & 945 & & & 1873 & 7556 & & \\
\hline 1692 & 963 & & & & & & \\
\hline 1772 & 1009 & & & & & & \\
\hline
\end{tabular}

Table IV. Thermophysical Parameters of the Ceramic Shell Mold Depending on Temperature ${ }^{[22]}$

\begin{tabular}{lccc}
\hline Temperature $(\mathrm{K})$ & Thermal Conductivity $(\mathrm{W} / \mathrm{m} \mathrm{K})$ & Specific Heat $(\mathrm{kJ} / \mathrm{kg} \mathrm{K})$ & Density $\left(\mathrm{kg} / \mathrm{m}^{3}\right)$ \\
\hline 295 & 0.987 & 0.934 & 1821.4 \\
572 & 0.903 & 1.160 & 1.270 \\
872 & 0.849 & 1.403 \\
1172 & 1.026 & 1.501 \\
1471 & 1.290 & 1.483 \\
1772 & 1.725 & \\
\hline
\end{tabular}

Table V. Thermophysical Parameters of the Insulation and Radiation Baffle vs Temperature ${ }^{[23]}$

\begin{tabular}{lccc}
\hline Temperature $(\mathrm{K})$ & Thermal Conductivity $(\mathrm{W} / \mathrm{m} \mathrm{K})$ & Density $\left(\mathrm{kg} / \mathrm{m}^{3}\right)$ & Heat Capacity $(\mathrm{kJ} / \mathrm{kg} \mathrm{K})$ \\
\hline 273 & 0.05 & 200 & 0.7 \\
873 & 0.1 & & \\
1173 & 0.2 & \\
1473 & 0.3 & & \\
1773 & 0.5 & & \\
\hline
\end{tabular}

Table VI. Interface Heat Transfer Coefficient Between the Casting and Mold as well as the Casting and Chill Plate

\begin{tabular}{|c|c|c|c|c|c|c|c|}
\hline $\begin{array}{l}\text { Temperature } \\
\left({ }^{\circ} \mathrm{C}\right)\end{array}$ & $\begin{array}{c}\text { Casting Mold } \\
\mathrm{HTC}\left(\mathrm{W} / \mathrm{m}^{2}\right. \\
\mathrm{K})^{[9]}\end{array}$ & $\begin{array}{c}\text { Temperature } \\
\left({ }^{\circ} \mathrm{C}\right)\end{array}$ & $\begin{array}{c}\text { Casting Chill } \\
\text { Plate HTC }(\mathrm{W} / \\
\left.\mathrm{m}^{2} \mathrm{~K}\right)^{[24]}\end{array}$ & $\begin{array}{l}\text { Temperature } \\
(\mathrm{K})\end{array}$ & $\begin{array}{l}\text { Chill Plate } \\
\text { Water HTC } \\
\left(\mathrm{W} / \mathrm{m}^{2} \mathrm{~K}\right)^{[18]}\end{array}$ & $\begin{array}{l}\text { Temperature } \\
\text { (K) }\end{array}$ & $\begin{array}{l}\text { Chill Plate } \\
\text { Mold HTC } \\
\left(\mathrm{W} / \mathrm{m}^{2} \mathrm{~K}\right)^{[9]}\end{array}$ \\
\hline 773 & 50 & 1473 & 196 & 293 & 5000 & 293 to 1700 & 20 \\
\hline 1073 & 100 & 1538 & 360 & & & & \\
\hline 1273 & 180 & 1633 & 390 & & & & \\
\hline 1473 & 300 & 1673 & 500 & & & & \\
\hline 1593 & 400 & 1773 & 750 & & & & \\
\hline 1773 & 750 & & & & & & \\
\hline
\end{tabular}


Table VII. Values of Technologic Parameters and the Geometry of Blades Applied During the Performed Numerical Simulations of the Directional Solidification Process

\begin{tabular}{|c|c|c|c|c|}
\hline Effect to be Examined & $\begin{array}{l}\text { Withdrawal Velocity } \\
(\mathrm{mm} / \mathrm{min})\end{array}$ & $\begin{array}{l}\text { Blade } \\
\text { Number }\end{array}$ & $\begin{array}{c}\text { Heater Temperature } \\
{\left[\mathrm{K}\left({ }^{\circ} \mathrm{C}\right)\right]}\end{array}$ & $\begin{array}{c}\text { Pouring Temperature } \\
{\left[\mathrm{K}\left({ }^{\circ} \mathrm{C}\right)\right]}\end{array}$ \\
\hline \multirow[t]{3}{*}{ Casting Shape } & 3 & 1 & $1793(1520)$ & $1780(1507)$ \\
\hline & 3 & 2 & $1793(1520)$ & $1738(1465)$ \\
\hline & 3 & 3 & $1793(1520)$ & $1758(1485)$ \\
\hline \multirow[t]{2}{*}{ Withdrawal Velocity } & $1,3,5$ & 2 & $1793(1520)$ & $1738(1465)$ \\
\hline & $1,3,5$ & 3 & $1793(1520)$ & $1758(1485)$ \\
\hline Withdrawal Velocity & $0.5,1,2,3,4,5$ & 3 & $1793(1520)$ & $1758(1485)$ \\
\hline \multirow[t]{6}{*}{ Heater Temperature } & 3 & 1 & $1723(1450)$ & $1780(1507)$ \\
\hline & 3 & 1 & $1793(1520)$ & $1780(1507)$ \\
\hline & 3 & 1 & $1843(1570)$ & $1780(1507)$ \\
\hline & 3 & 3 & $1723(1450)$ & $1758(1485)$ \\
\hline & 3 & 3 & $1793(1520)$ & $1758(1485)$ \\
\hline & 3 & 3 & $1843(1570)$ & $1758(1485)$ \\
\hline \multirow[t]{4}{*}{ Pouring Temperature } & 3 & 1 & $1793(1520)$ & $1723(1450)$ \\
\hline & 3 & 1 & $1793(1520)$ & $1843(1570)$ \\
\hline & 3 & 3 & $1793(1520)$ & $1723(1450)$ \\
\hline & 3 & 3 & $1793(1520)$ & $1843(1570)$ \\
\hline
\end{tabular}

Those solidification parameters were determined for better characterization and control of the manufacturing process of single-crystal castings made of nickel superalloy. The average cooling rate $C$ at liquidus isotherm $T_{\mathrm{L}}=1655 \mathrm{~K}\left(1382{ }^{\circ} \mathrm{C}\right)$ was assumed as the difference of temperatures between values $\Delta T=1660 \mathrm{~K}$ and $1650 \mathrm{~K}\left(1387^{\circ} \mathrm{C}\right.$ and $\left.1377^{\circ} \mathrm{C}\right)$ for time $\Delta t$ based on the equation [Figure 5(a)]:

$$
C=\frac{\Delta T}{\Delta t}
$$

Value $\Delta t$ was calculated as the time between reaching the temperature of $1660 \mathrm{~K}$ and $1650 \mathrm{~K}\left(1387^{\circ} \mathrm{C}\right.$ and $1377^{\circ} \mathrm{C}$ ). The temperature range $\Delta T$ was chosen to calculate the average cooling rate in the area near the liquidus temperature $\left[1665 \mathrm{~K}\left(1382{ }^{\circ} \mathrm{C}\right)\right]$. The solidification rate $v$ at the test points was obtained by applying the established cooling rate $C$ and temperature gradient $G$ into following relation:

$$
v=\frac{C}{G}
$$

It was supposed that shifting the velocity of the liquidus isotherm describes the location of the dendrite tip and solidification rate. Temperature gradient $G$ was determined for time when the liquidus isotherm was located at test point $z_{i}$ of the blade (Figure 5). For this purpose, the temperature distribution among three test points $z_{i+1}, z_{i}, z_{i-1}$ was established (Figure 5(b)) by fitting the second-order polynomial for time $t_{i}$ when liquidus isotherm $T_{L}$ reached the test point $\mathrm{z}_{\mathrm{i}}$ :

$$
T(z)=a_{2} z^{2}+a_{1} z+a_{0}
$$

where $a_{2}, a_{1}, a_{0}$ are the polynomial coefficients, and $\mathrm{z}$ is the distance measured along the line of test points $z_{i+1}, z_{i,} z_{i-1}$. Hence, the derivative of polynomial $T(\mathrm{z})$ in point $z_{i}$ determines the temperature gradient at the liquidus isotherm:

$$
G=\left(\frac{\mathrm{dT}}{\mathrm{dz}}\right)_{z=z_{\mathrm{i}}}
$$

The predicted temperature gradient at the liquidus isotherm and solidification rate were calculated using the RGL function from the ProCAST software. The predicted values of solidification parameters were established on the longitudinal section of casting along the profile containing the symmetry axis.

\section{E. Position of the Liquidus Isotherm Relative to the Radiation Baffle}

The actual temperature distribution was the basis for determining the position of the liquid isotherm regarding the radiation baffle $L$ (Figure 5(c)). The knowledge of the time to reach the liquidus at the casting points $t_{i}$ and the withdrawal velocity $v_{\mathrm{w}}$ of the mold allowed the calculation of the distance shift of the chill plate $l_{1}$ relative to its initial position $l_{\mathrm{w}}$ according to equation:

$$
l_{1}=v_{\mathrm{w}} \cdot\left(t_{i}-t_{\mathrm{h}}\right)
$$

where $v_{\mathrm{w}}$ is the withdrawal velocity of the mold, $t_{\mathrm{i}}$ is the time to reach the liquidus isotherm at the test point $z_{i}$, and $t_{\mathrm{h}}$ is the time of the withdrawal start of the filled mold.

Hence, the distance between the chill plate and surface of the radiation baffle $l_{2}$ was calculated from the relation:

$$
l_{2}=l_{1}+l_{\mathrm{w}}
$$

The position of the liquidus isotherm in the blade relative to radiation baffle $L$ was then defined as the difference of distances $l_{2}$ and $l_{z}$ : 


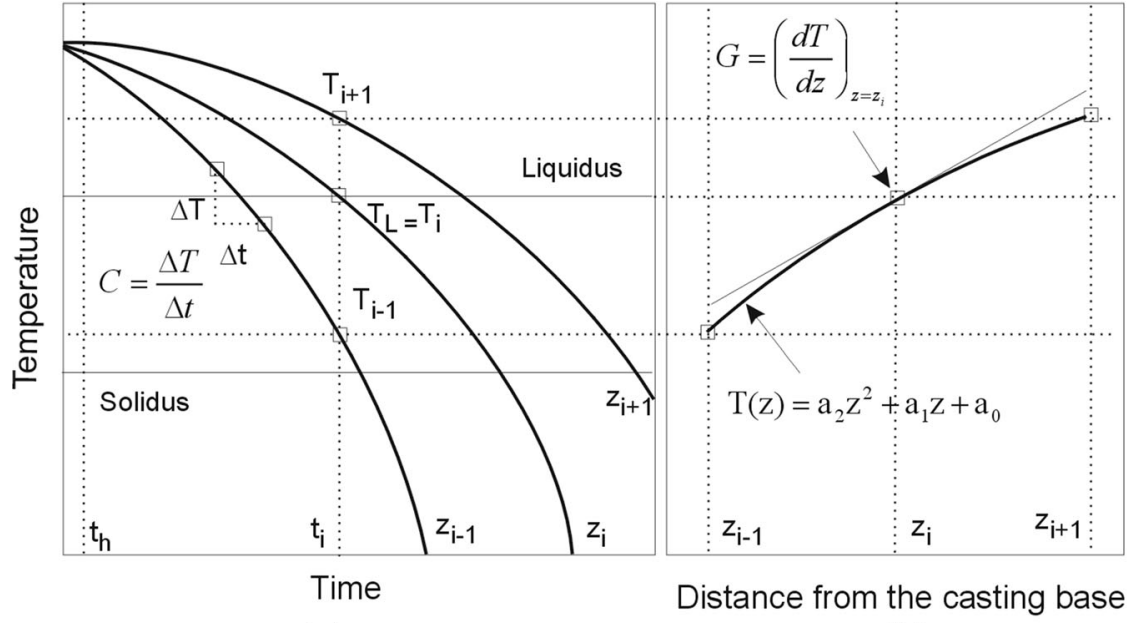

(a) (b)

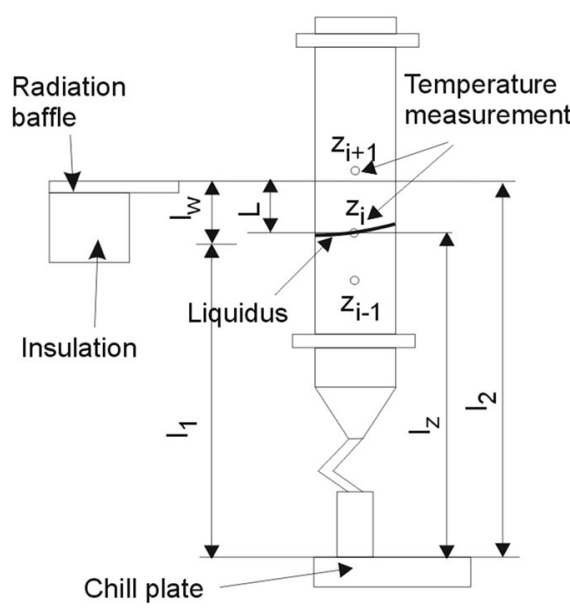

(c)

Fig. 5-Scheme of calculation of: $(a)$ cooling rate, $(b)$ temperature gradient and $(c)$ position of the liquidus isotherm in relation to the radiation baffle along the blade height based on temperature-time curves, where: $C$ is the cooling rate, $G$ is the temperature gradient at the liquidus isotherm, $T_{\mathrm{L}}=T_{\mathrm{i}}$ is the liquidus temperature at height $z_{\mathrm{i}}, T_{\mathrm{i}+1}$ is the temperature at height $z_{\mathrm{i}+1}, T_{\mathrm{i}-1}$ is the temperature at height $z_{\mathrm{i}-1}, L$ is the distance of the liquidus isotherm from the radiation baffle, $l_{\mathrm{w}}$ is the position of the chill plate before withdrawal of the mold, $l_{1}$ is the distance of withdrawal of the chill plate, $l_{\mathrm{z}}$ is the distance of the liquidus isotherm from the chill plate, $l_{2}$ is the distance of the chill plate from the radiation baffle, $t_{\mathrm{i}}$ is the time required to reach the liquidus isotherm at test point $z_{\mathrm{i}}, t_{\mathrm{h}}$ is the time of withdrawal start of the filled mold, $\mathrm{a}_{2}, \mathrm{a}_{1}, \mathrm{a}_{0}$ are the polynomial coefficients, $z$ is the distance measured along the line of test points $z_{\mathrm{i}+1}, z_{\mathrm{i}}, z_{\mathrm{i}-1}, \Delta t$ is the time between reaching the temperature of $1660 \mathrm{~K}$ and $1650 \mathrm{~K}\left(1387{ }^{\circ} \mathrm{C}\right.$ and $\left.1377^{\circ} \mathrm{C}\right)$, and $\Delta T$ is the difference of temperatures between values $1660 \mathrm{~K}$ and $1650 \mathrm{~K}\left(1387{ }^{\circ} \mathrm{C}\right.$ and $\left.1377{ }^{\circ} \mathrm{C}\right)$.

$$
L=l_{2}-l_{z}
$$

where $l_{z}$ is the distance of the liquidus isotherm from the chill plate.

\section{RESULTS}

\section{A. Temperature Distribution and Simulation Validation}

Two time periods of temperature measurement were distinguished. In the first instance, the ceramic shell mold was placed on the chill plate in the heating area, heated up and kept at constant temperature. During the next stage, the mold was poured with liquid metal and withdrawn at specific velocity from the heating to cooling area of the furnace (Figure 6).

The analysis of results showed that approximately 100 to 300 seconds after pouring, the liquid metal reached its maximum temperature as a result of the thermal interaction of the mold and metal (Figure 6). The further cooling of the alloy occurred with the withdrawal of the mold from the heating to cooling area of the furnace. The withdrawal of the mold was started 40 seconds after pouring. A continuous decrease of temperature was recorded in particular test points until the process was finished. It was observed that the shape of cooling curves obtained from relation $T=\mathrm{f}(\mathrm{t})$ changed in the root, airfoil and platforms depending on shape of blades and withdrawal velocity of the mold. The shape of curves was similar for both parts of the cast process, from pouring the mold to beginning the liquid alloy solidification and also from reaching the solidus to the end of cooling. The shape of curves changed between the liquidus and solidus temperatures, especially for the root and platforms. The increase of root and platform thicknesses as well as the withdrawal velocity of the mold led to the intensification of that phenomenon, also in the blade airfoil (Figures 6(a) and (d)). Reaching the liquidus by the liquid alloy started the solidification in the form of an intensive precipitation of $\gamma$ phase accompanied by additional release of latent heat. The intensity of solid fraction formation was the highest during the initial stage of transition. Afterwards, it decreased gradually until the solidification temperature of eutectic in the nickel superalloy was reached. ${ }^{[25]}$ The solidification process ended when the alloy reached the solidus temperature $\left(1320{ }^{\circ} \mathrm{C}\right) .{ }^{[20]}$

The measured temperature distribution was a basis for the verification of thermophysical parameters of materials and the boundary conditions applied in the numerical simulation (Figure 7). Good conformity between the actual and predicted temperatures was observed for blades 2 withdrawn at 3 and $5 \mathrm{~mm} / \mathrm{min}$.

\section{B. Solidification Parameters}

\section{The effect of blade geometry}

The effect of blade geometry on solidification parameters was analyzed using constant mold withdrawal velocity of $3 \mathrm{~mm} / \mathrm{min}$ (Figure 9 ). The actual and predicted temperature gradient $G$ was determined along the height of blades 1-3, which were withdrawn at the same velocity of $3 \mathrm{~mm} / \mathrm{min}$ and had variable thicknesses of root and platforms (Figure 9(a)). The actual temperature gradient was calculated using the temperaturetime (Figure 6) and then temperature-distance curves (Figure 8). The cooling curves were the basis for determining the time to reach the liquidus isotherm at the test points and then to calculate the temperature 


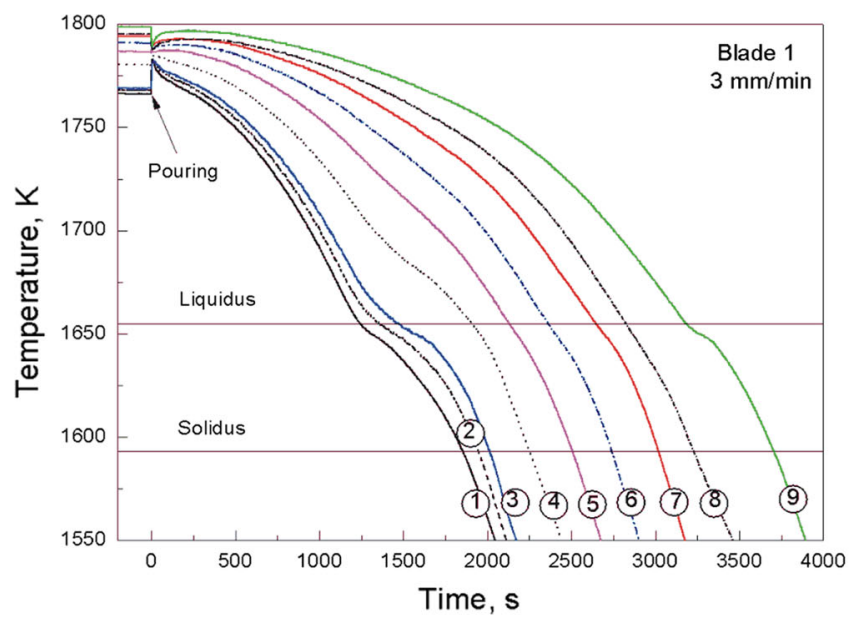

(a)

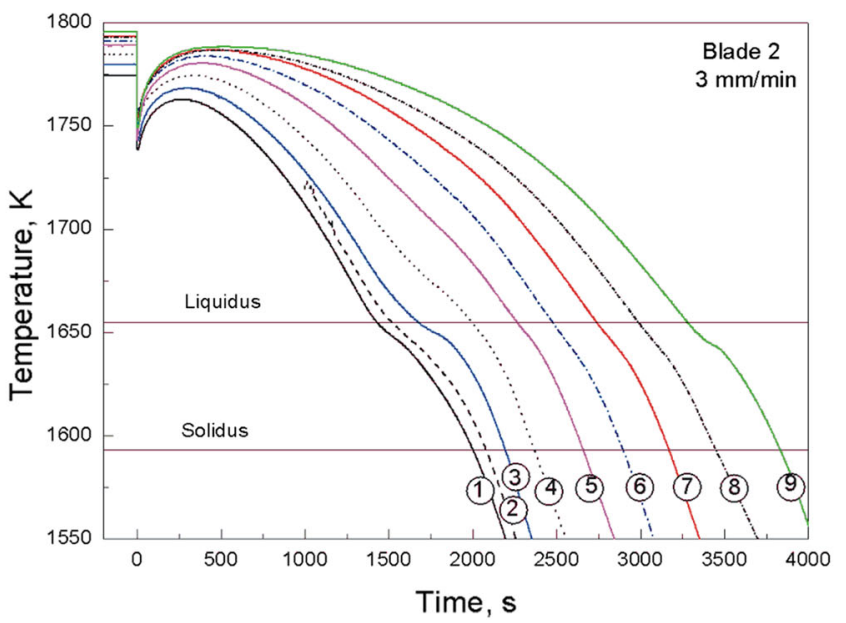

(c)

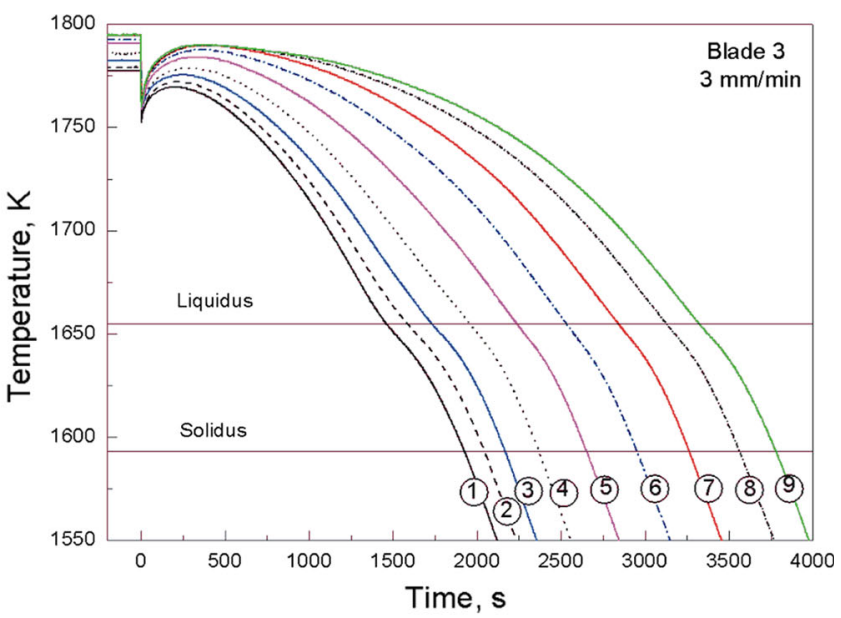

(b)

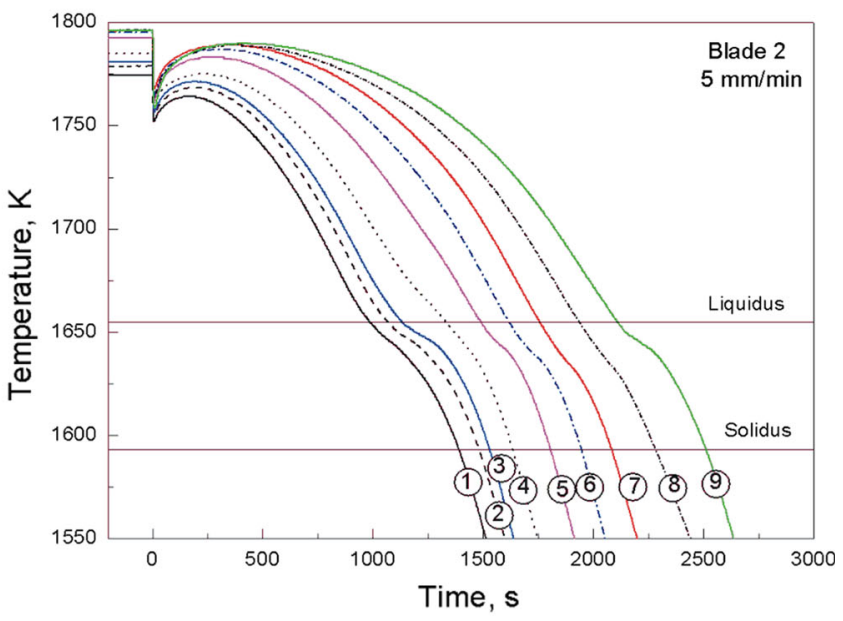

(d)

Fig. 6-Measured temperature distribution along the height of blades 1,2 and 3 withdrawn at $3 \mathrm{~mm} / \mathrm{min}(a$ through $c)$ and $5 \mathrm{~mm} / \mathrm{min}(d)$.

distribution along the casting height. Figure 8 illustrates the examples of temperature distribution near the test point (liquidus isotherm) established by fitting the second-order polynomial and the calculated temperature gradient at the liquidus isotherm.

It was established that the value of the temperature gradient varied along the length of the blade (Figure 9(a)). The actual and predicted temperature gradient changed in the same way as in the case of blade 1 and 2. On the other hand, in the case of blade 3 with a constant thickness of $7 \mathrm{~mm}$, the temperature gradient was more homogeneously distributed along height. The highest $G$ was attained in the area of the cross section where the selector was connected to the continuer. It equaled 47,38 and $27 \mathrm{~K} / \mathrm{cm}$ for blades 1,2 and 3 , respectively (Figure 9(a)). The increase of distance from the casting base (continuer section) resulted in a significant drop of $G$ until the lowest value in root was reached. The temperature gradient in the lower platform intensively increased until it attained the maximum value in the area, in which the section decreased (platform/airfoil transition). It was established that $G$ increased with increasing root thickness (blade 1 and 2).
The drop of temperature gradient could be observed in the area above the platform, until the minimum value in blade 1 and 2 was reached. The value rose again in the upper part of the airfoil and the area where the blade section changed (airfoil/platform transition). However, no such change of $G$ in the airfoil was observed for constant blade sections (blade 3) (Figure 9(a)).

The solidification rate $v$ was determined along the height of blades 1, 2 and 3 (Figure 9(b)). It was established that the solidification rate differed from the mold withdrawal velocity of $3 \mathrm{~mm} / \mathrm{min}$. It intensively increased in the continuer and reached the maximum value, higher than the withdrawal velocity, at a height of $10 \mathrm{~mm}$ (independently of the root thickness). The value of the solidification rate decreased gradually in the root and in the area where the casting thickness changed (lower platform/airfoil transition). Afterwards, it intensively increased up to the maximum value (in the airfoil), which depended on root thickness of blade 1 and 2. It decreased again in the upper part of the airfoil and the area of airfoil/platform transition where the casting section increased. The solidification rate was constant at the distance of $60 \mathrm{up}$ to $130 \mathrm{~mm}$ from the base of blade 3 . 


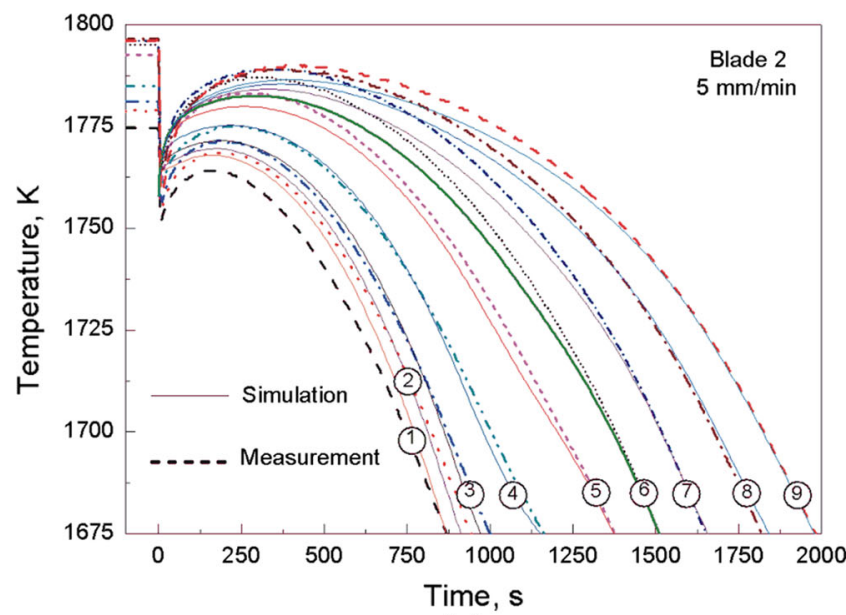

(a)

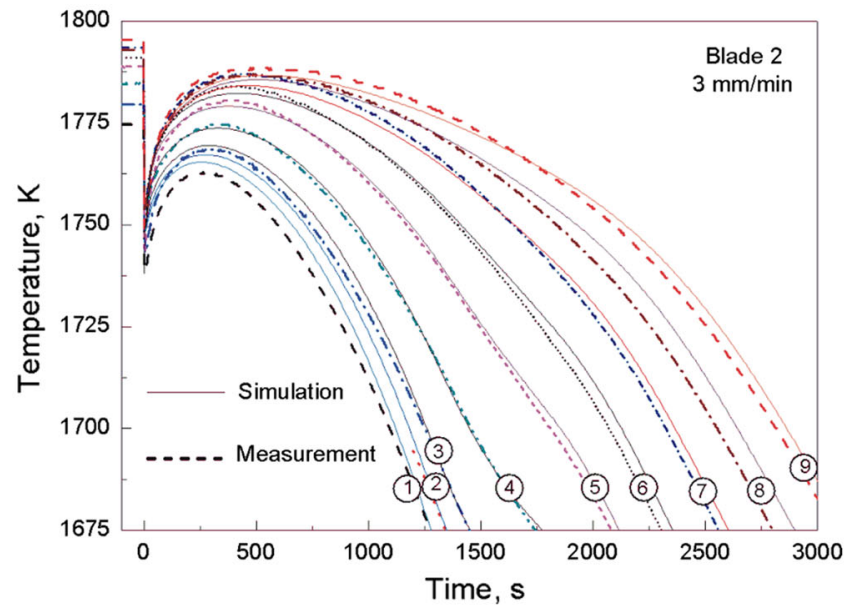

(c)

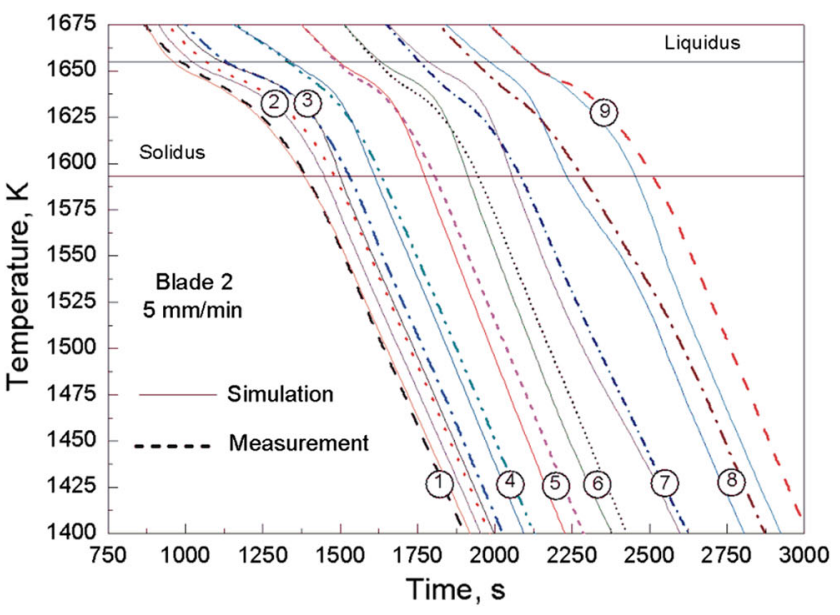

(b)

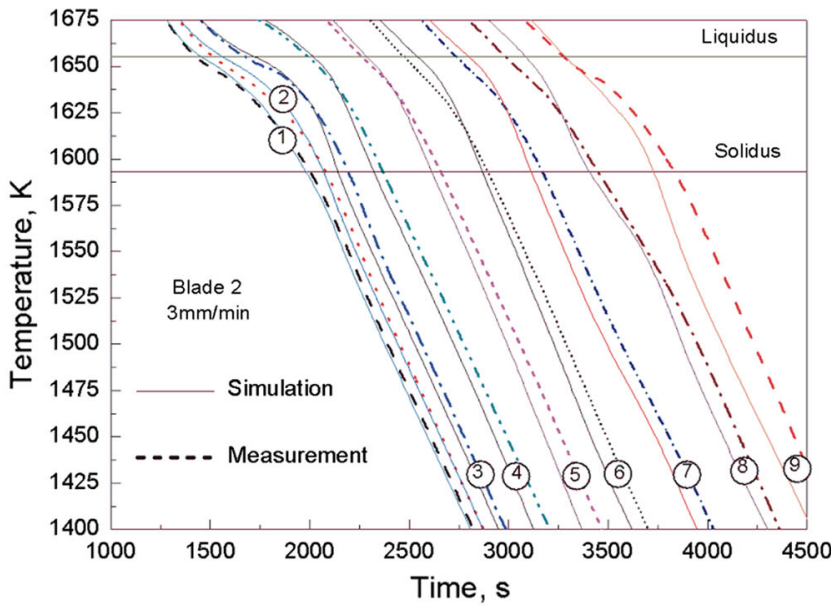

(d)

Fig. 7-Actual and predicted temperature distribution along the height of blade 2 withdrawn at velocities of $5 \mathrm{~mm} / \mathrm{min}(a, b)$ and $3 \mathrm{~mm} / \mathrm{min}(c$, d).

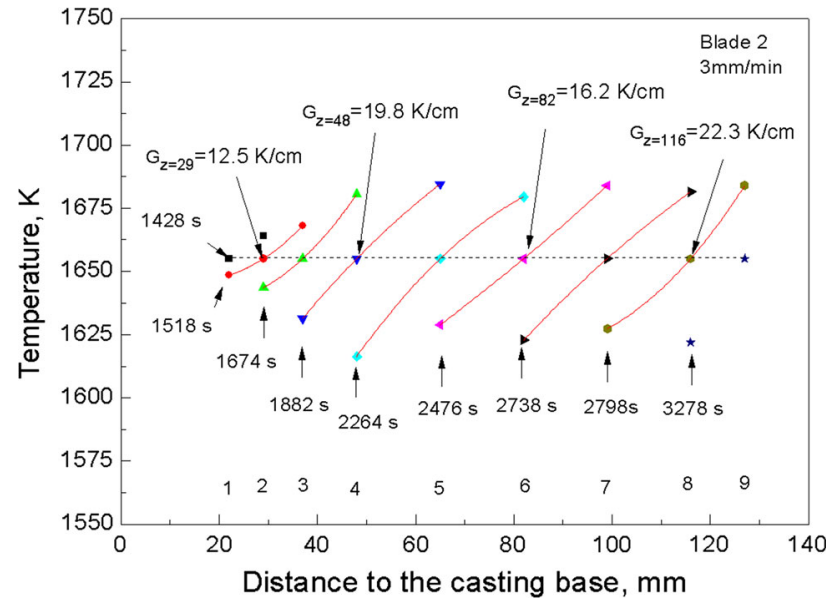

Fig. 8-Temperature distribution $v s$ distance from the casting base for the time required to reach the liquidus at test points $1-9$. Temperature gradient at the liquidus calculated at points $2-29,4-48$, 6-82 and 8-118 $\mathrm{mm}$.
The numerical simulation was used as a basis for establishing the solidification parameters on the longitudinal section of blades 1, 2 and 3 (Figure 10), which attained different values in their internal and external areas. The temperature gradients were the highest in the external area, and their values decreased toward the central rod independently of the blade geometry (Figures 10(a) through (c)), whereas the solidification rates acquired similar values in both the internal and external areas of the blade (Figures 10(d) through (f)).

The liquidus isotherm of all blades was located below the radiation baffle in the area of the continuator (Figure 11). The value of $L$ continuously decreased with increasing distance from the casting base. On the other hand, it rose in the area where the blade section changed (point 4). The liquidus isotherm was located in the heating area (above the radiation baffle) at the height of the blade larger than approximately $70 \mathrm{~mm}$. It was established that the increase of root thickness (blade 1) additionally led to the shift of the liquidus isotherm toward the heating area. 


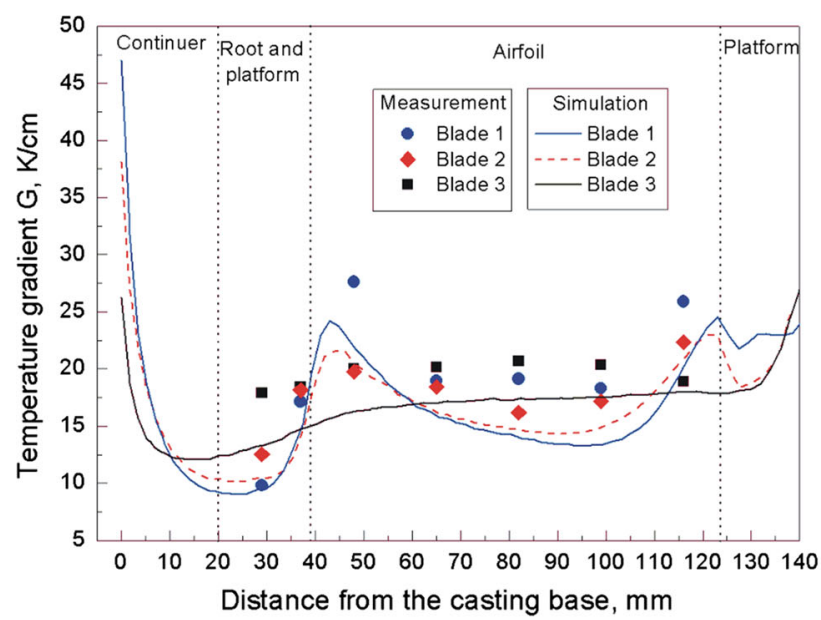

(a)

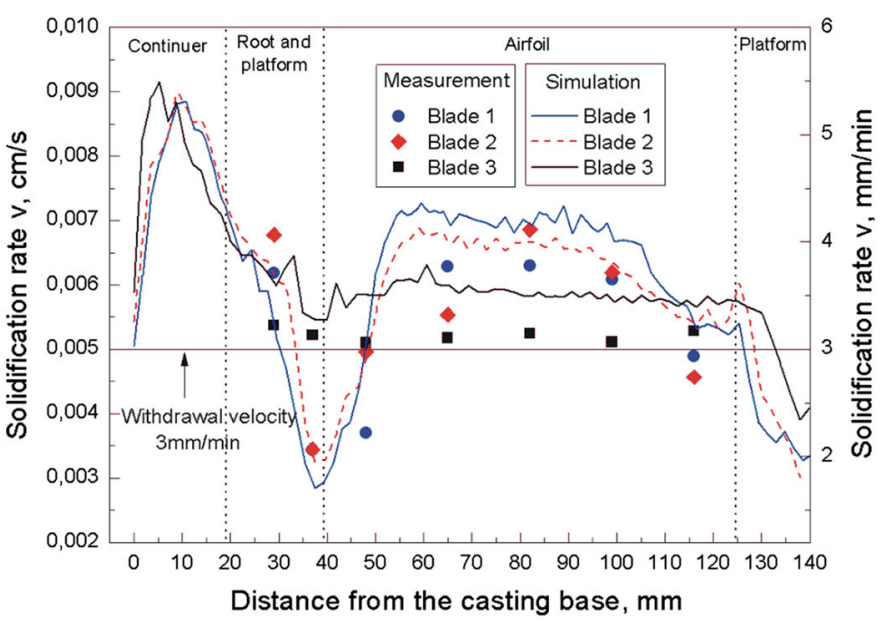

(b)

Fig. 9-Measured (symbols) and predicted (curves) of: (a) temperature gradient and (b) solidification rate along the height of blades withdrawn at $3 \mathrm{~mm} / \mathrm{min}$ velocity.

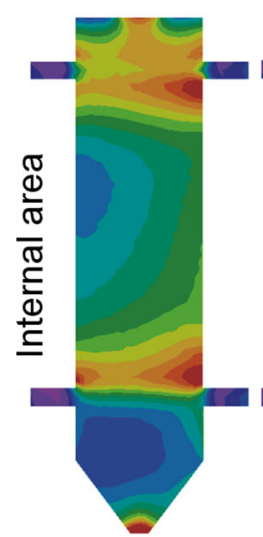

(a)

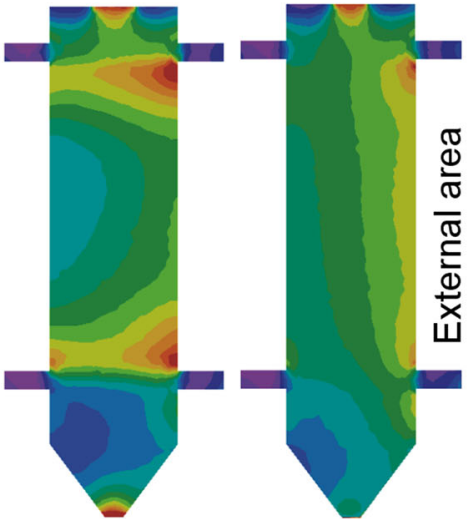

(b)

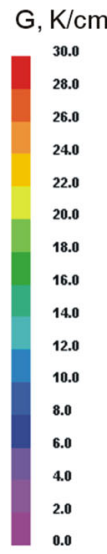

(c)

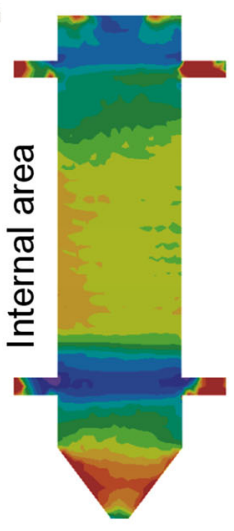

(d)

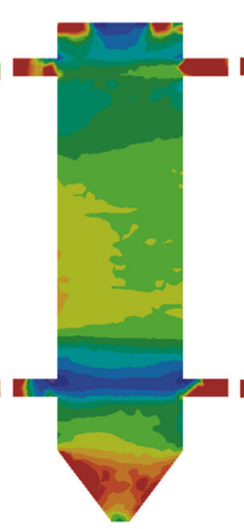

(e)

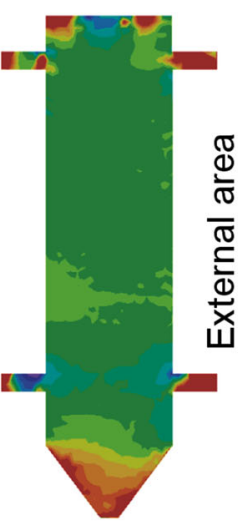

(f)

Fig. 10-Numerical simulation of distribution of: ( $a$ through $c$ ) temperature gradient and ( $d$ through $f$ ) solidification rate at the longitudinal section of blade $1(\mathrm{a}, \mathrm{d}), 2$ (b, e) and 3 (c, f) characterized by different root thicknesses and withdrawn at $3 \mathrm{~mm} / \mathrm{min}$ velocity.

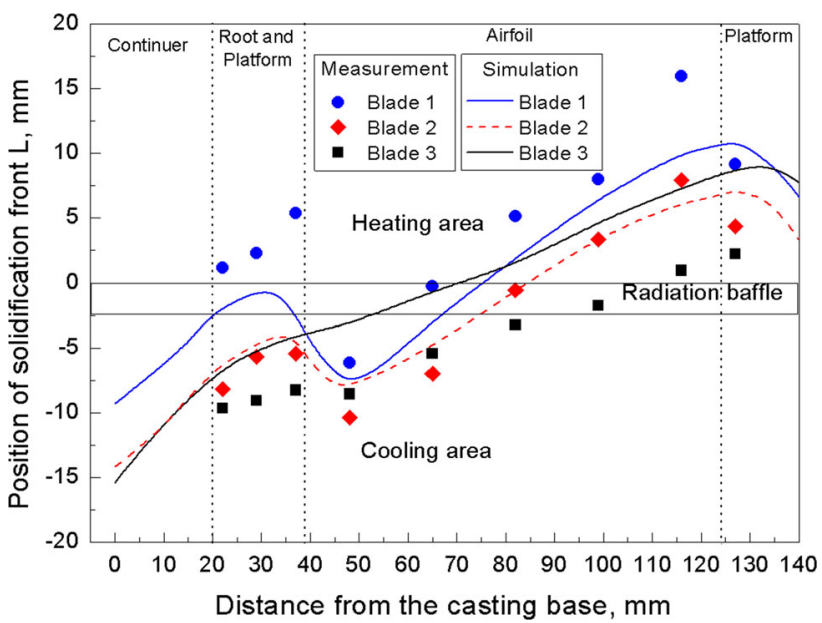

Fig. 11-Measured (curves) and predicted (symbol) positions of the liquidus isotherm along the height of blades withdrawn at $3 \mathrm{~mm} / \mathrm{min}$ velocity.

\section{The effect of the mold withdrawal velocity}

The effect of the mold withdrawal velocity on the predicted and measured solidification parameters was determined for blades 1 and 3 withdrawn at the velocity of 1,3 and $5 \mathrm{~mm} / \mathrm{min}$ (Figure 12). It was determined that the solidification rate differed from the withdrawal velocity of the mold, and it simultaneously changed along the casting height (Figure 12(b)). The rate was lower in the area where casting thickness altered (point 3 ) and higher in the remaining blade parts compared with the withdrawal velocity of the mold. The increase of that velocity led to an increase of the difference between the solidification rate and withdrawal velocity. The analysis of the obtained research results allowed the statement that a change in the cross-sectional area of blade casting resulted in disturbance of the solidification rate (Figure 12(b)). The fastest increase of the solidification rate and shift of the liquidus isotherm was observed for blade 2 at the withdrawal velocity of $5 \mathrm{~mm} /$ min. The solidification rate of approximately $8 \mathrm{~mm} / \mathrm{min}$ 


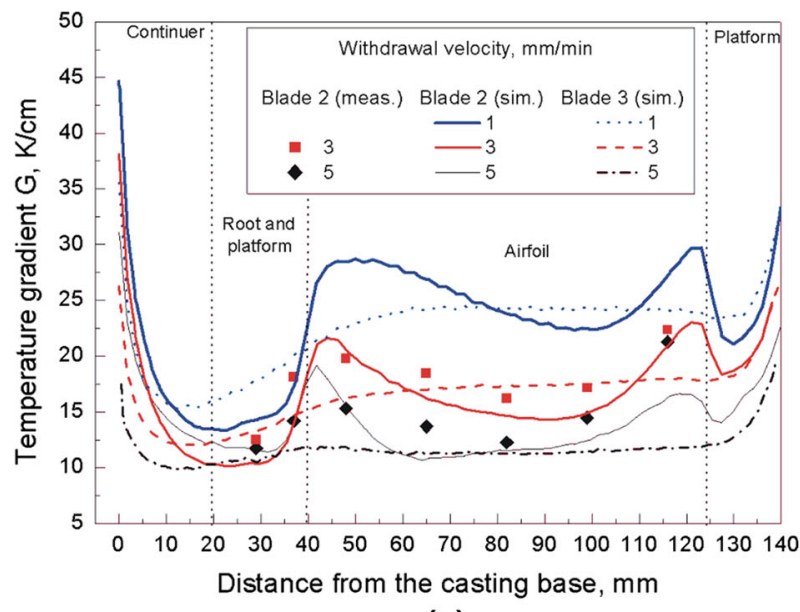

(a)

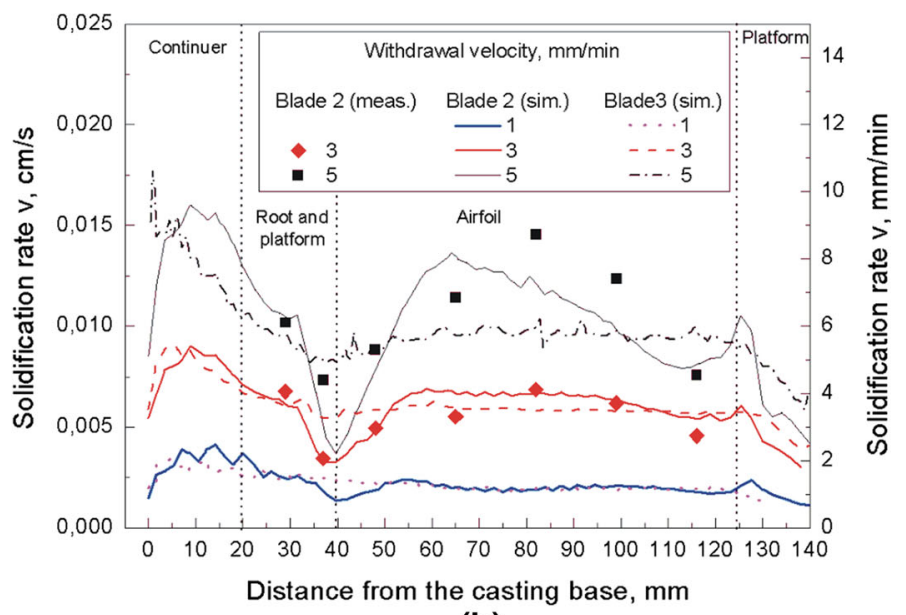

(b)

Fig. 12-Measured (symbols) and simulated (curves) of: (a) temperature gradient and (b) solidification rate along the height of blade 2 and 3 withdrawn at velocities of 1,3 and $5 \mathrm{~mm} / \mathrm{min}$.

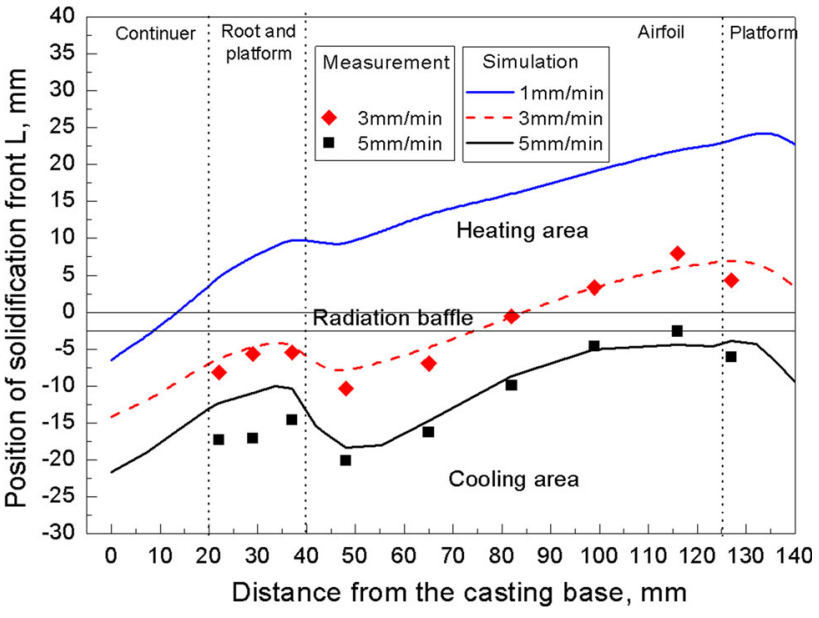

Fig. 13-Measured (symbol) and predicted (curves) positions of the liquidus isotherm along the height of blade 2, withdrawn at velocities of 1,3 and $5 \mathrm{~mm} / \mathrm{min}$.

was reached for a withdrawal velocity of $5 \mathrm{~mm} / \mathrm{min}$ at the height of $70 \mathrm{~mm}$ for blade 2 . Above that area, it intensively dropped.

The temperature gradient was set at the liquidus isotherm along blade 2 and 3 withdrawn at velocity 1, 3 and $5 \mathrm{~mm} / \mathrm{min}$ (Figure 12(a)). It was determined that its value depended on the withdrawal velocity of the mold. The temperature gradient, along the casting height, differentiated according to a specific trend. A certain temperature gradient was established in the selector/continuer transition area. Afterwards, it decreased drastically in the continuer and increased significantly at the height of 35 to $45 \mathrm{~mm}$ (platform/airfoil transition) (Figure 12(a)). It attained its maximum value $(28 \mathrm{~K} / \mathrm{cm})$ at the height of $45 \mathrm{~mm}$ (airfoil) for the withdrawal velocity of $1 \mathrm{~mm} / \mathrm{min}$ (blade 2). However, a visible decrease of temperature gradient was detected in the areas above the height of $41 \mathrm{~mm}$ at the withdrawal velocity of $5 \mathrm{~mm} / \mathrm{min}$. It was determined that the change of temperature gradient in the area of the platform/ airfoil got larger when the withdrawal velocity decreased (Figure 12(a)). It was determined that for all withdrawal velocities of blade 2, the temperature gradient reduced to its minimum value in the airfoil. For velocity of $5 \mathrm{~mm} / \mathrm{min}$, it was $12 \mathrm{~K} / \mathrm{cm}$ at the height of approximately $82 \mathrm{~mm}$ (measurement data). Lowering the withdrawal velocity resulted in the shift of the minimum gradient toward the upper part of the blade airfoil. The value of $22 \mathrm{~K} / \mathrm{cm}(1 \mathrm{~mm} / \mathrm{min})$ was obtained at $100 \mathrm{~mm}$ height. The temperature gradient increased again in the upper part of the airfoil and in the area of the cross-sectional change (airfoil/upper platform transition), whereas in the blade with constant thickness (blade 3), the lowest temperature gradient was solely obtained in the continuer at all withdrawal velocities (Figure 12(a)).

The location of the liquidus isotherm along the casting height of blade 2 and 3 was determined regarding the location of radiation baffle $L$ for the withdrawal velocity of 1,3 and $5 \mathrm{~mm} / \mathrm{min}$ (Figure 13). It was established that the distance $L$ changed along the casting height depending on the withdrawal velocity of the mold. The liquidus isotherm in the selector and root connect area was located below the radiation baffle (cooling area of the furnace) at the distance of approximately 7 and $22 \mathrm{~mm}$ for the withdrawal velocity of 1 and $5 \mathrm{~mm} / \mathrm{min}$, respectively. Independently of the withdrawal velocity of the mold, a large increase of distance $L$ was observed above the lower platform at the blade height of $45 \mathrm{~mm}$. For the withdrawal velocity of $5 \mathrm{~mm} /$ min, the distance between the liquidus isotherm in the casting and radiation baffle decreased gradually along the airfoil to the value of approximately $L=-5 \mathrm{~mm}$ at the height of $110 \mathrm{~mm}$. The reduction of the withdrawal velocity down to $1 \mathrm{~mm} / \mathrm{min}$ resulted in the shift of the liquidus isotherm above the radiation baffle to the heating area of the furnace. At the withdrawal velocity of $3 \mathrm{~mm} / \mathrm{min}$, the blade solidified partially below and above the radiation baffle when the liquidus isotherm occurred at the height of approximately $70 \mathrm{~mm}$ from the 


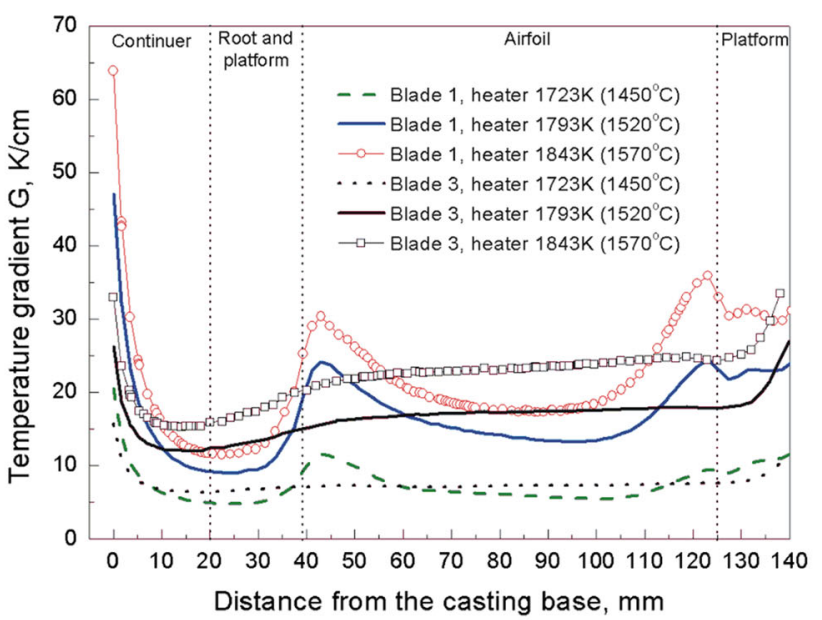

(a)

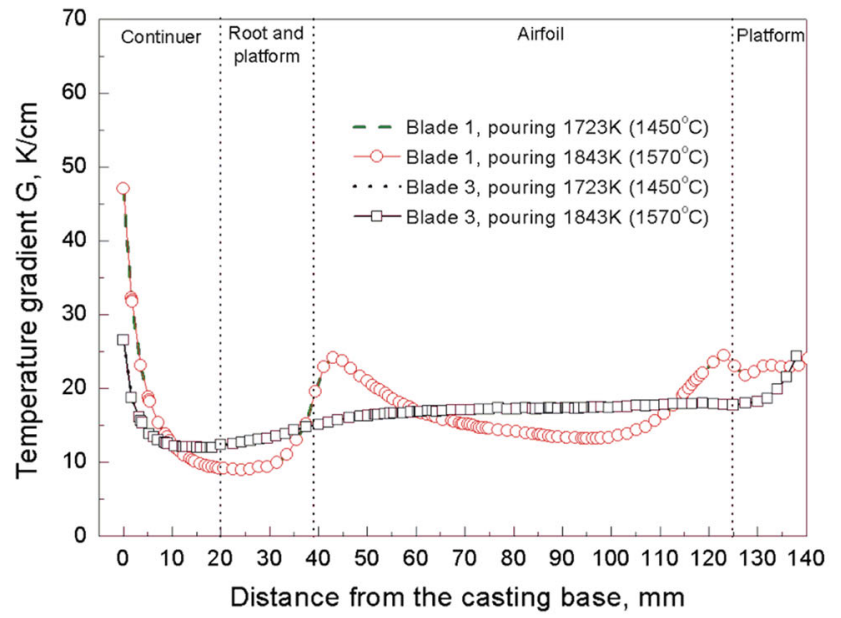

(c)

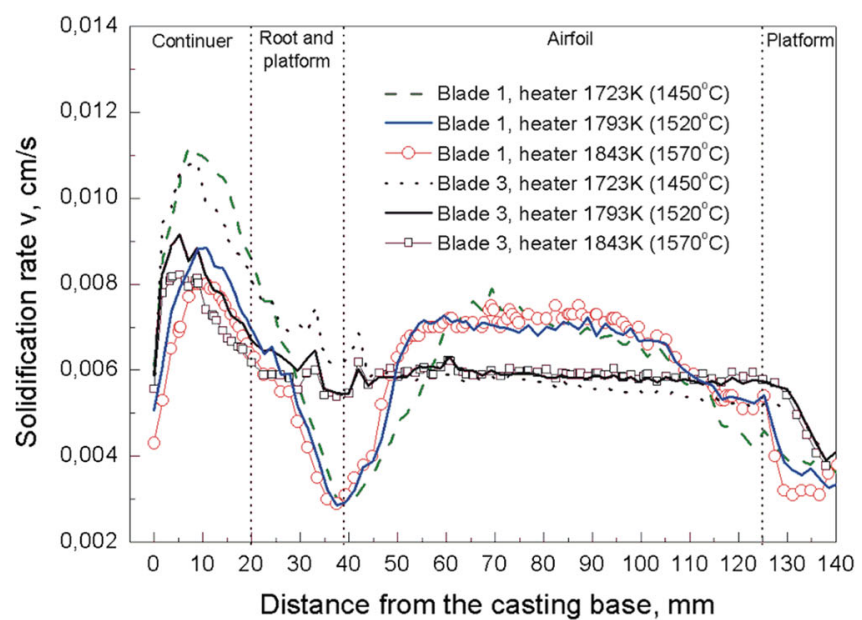

(b)

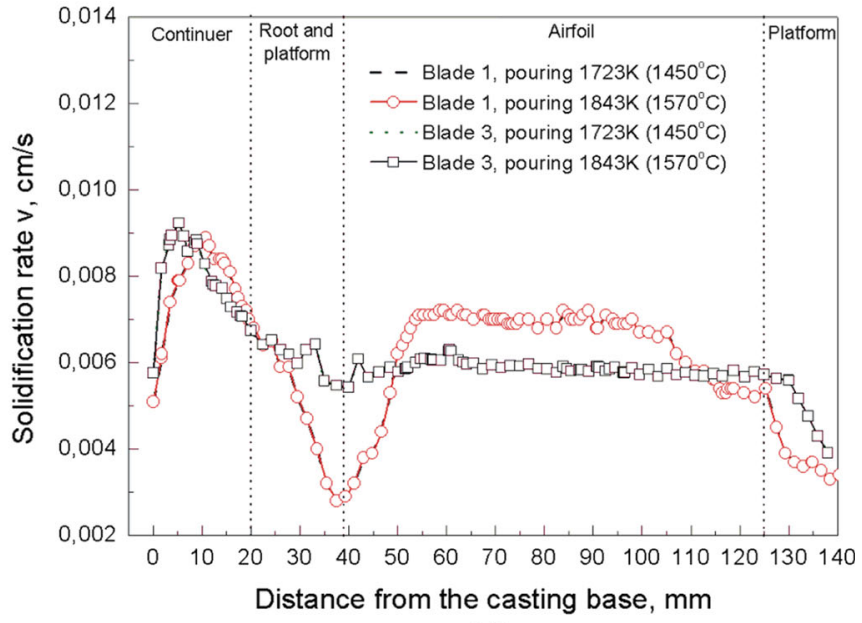

(d)

Fig. 14 - Predicted temperature gradient $(a, c)$ and solidification rate $(b, d)$ in the function of the heater and pouring temperatures along the height of blade 1 and 3, withdrawn at a velocity of $3 \mathrm{~mm} / \mathrm{min}$.

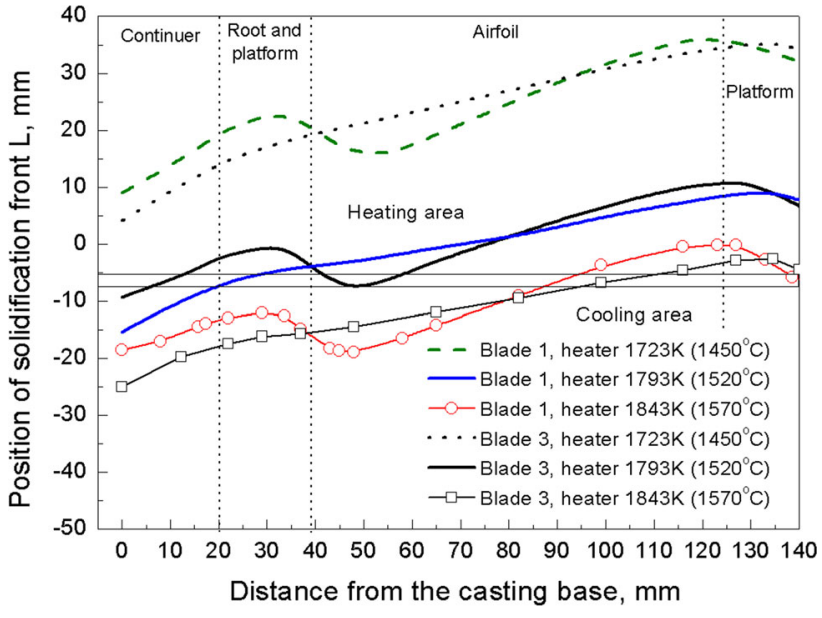

Fig. 15-Position of the liquidus isotherm along the height of blade 1 and 3 vs the temperature of heaters. casting base. However, at a velocity of $5 \mathrm{~mm} / \mathrm{min}$, the liquidus isotherm was located below the radiation baffle along the whole blade height (Figure 13).

\section{Effect of mold and pouring temperature}

The performed analysis of temperature distribution (Figure 6) allowed concluding that different pouring temperatures can affect the solidification process of the blade. Based on this statement, the influence of the pouring temperature on the predicted solidification parameters in blade 1 and 3, withdrawn at velocity $3 \mathrm{~mm} / \mathrm{min}$, was determined (Figure 14). The variable heater temperatures $[1723 \mathrm{~K}, 1793 \mathrm{~K}$ and $1843 \mathrm{~K}$ $\left(1450{ }^{\circ} \mathrm{C}, 1520^{\circ} \mathrm{C}\right.$ and $\left.\left.1570{ }^{\circ} \mathrm{C}\right)\right]$ as well as pouring temperature of $1723 \mathrm{~K}$ and $1843 \mathrm{~K}\left(1450{ }^{\circ} \mathrm{C}\right.$ and $1570{ }^{\circ} \mathrm{C}$ ) were assumed. It was determined that the heater temperature had a larger impact on the temperature gradient and solidification rate than the pouring temperature. The temperature gradient increased along 


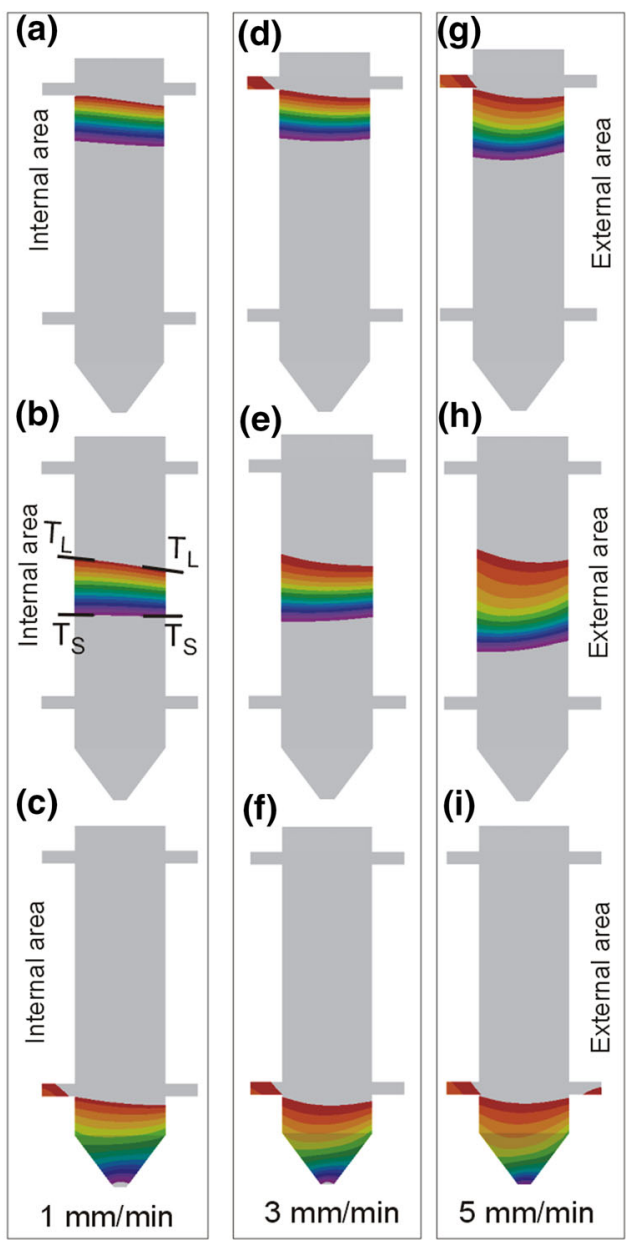

Fig. 16 - Shape of the mushy zone along the height of blade 2 withdrawn at velocity $1(a$ through $c), 3(d$ through $f)$ and $5 \mathrm{~mm} / \mathrm{min}$ ( $g$ through $i$ ).

the whole length of blade 1 and 3 with increasing heater temperature (Figures 14(a) and (c)). In the airfoil and upper platform of blades, the solidification rate was similar for all the assumed heater temperatures. However, in the area of the root and continuator, the value was higher for the heater temperature of $1723 \mathrm{~K}$ $\left(1450{ }^{\circ} \mathrm{C}\right)$ than for $1843 \mathrm{~K}\left(1570{ }^{\circ} \mathrm{C}\right)$. It was established that the decrease of the pouring temperature from $1843 \mathrm{~K}\left(1570{ }^{\circ} \mathrm{C}\right)$ down to $1723 \mathrm{~K}\left(1450{ }^{\circ} \mathrm{C}\right)$ did not result in a drop of either the temperature gradient or solidification rate (Figures 14(c) and (d)).

The predicted location of the liquidus isotherm regarding the radiation baffle was determined for heater temperatures of $1723 \mathrm{~K}, 1793 \mathrm{~K}$ and $1843 \mathrm{~K}\left(1450{ }^{\circ} \mathrm{C}\right.$, $1520^{\circ} \mathrm{C}$ and $1570{ }^{\circ} \mathrm{C}$ ) for blades 1 and 3 being withdrawn at a velocity of $3 \mathrm{~mm} / \mathrm{min}$ (Figure 15). It was observed that the liquidus isotherm shifted toward the cooling area if the heater temperature rose. It was located above and below the radiation baffle for temperature values of $1843 \mathrm{~K}$ and $1723 \mathrm{~K}\left(1570{ }^{\circ} \mathrm{C}\right.$ and $1450{ }^{\circ} \mathrm{C}$ ), respectively. However, it was situated partially above and below the radiation baffle at $1793 \mathrm{~K}$ $\left(1520^{\circ} \mathrm{C}\right)$.

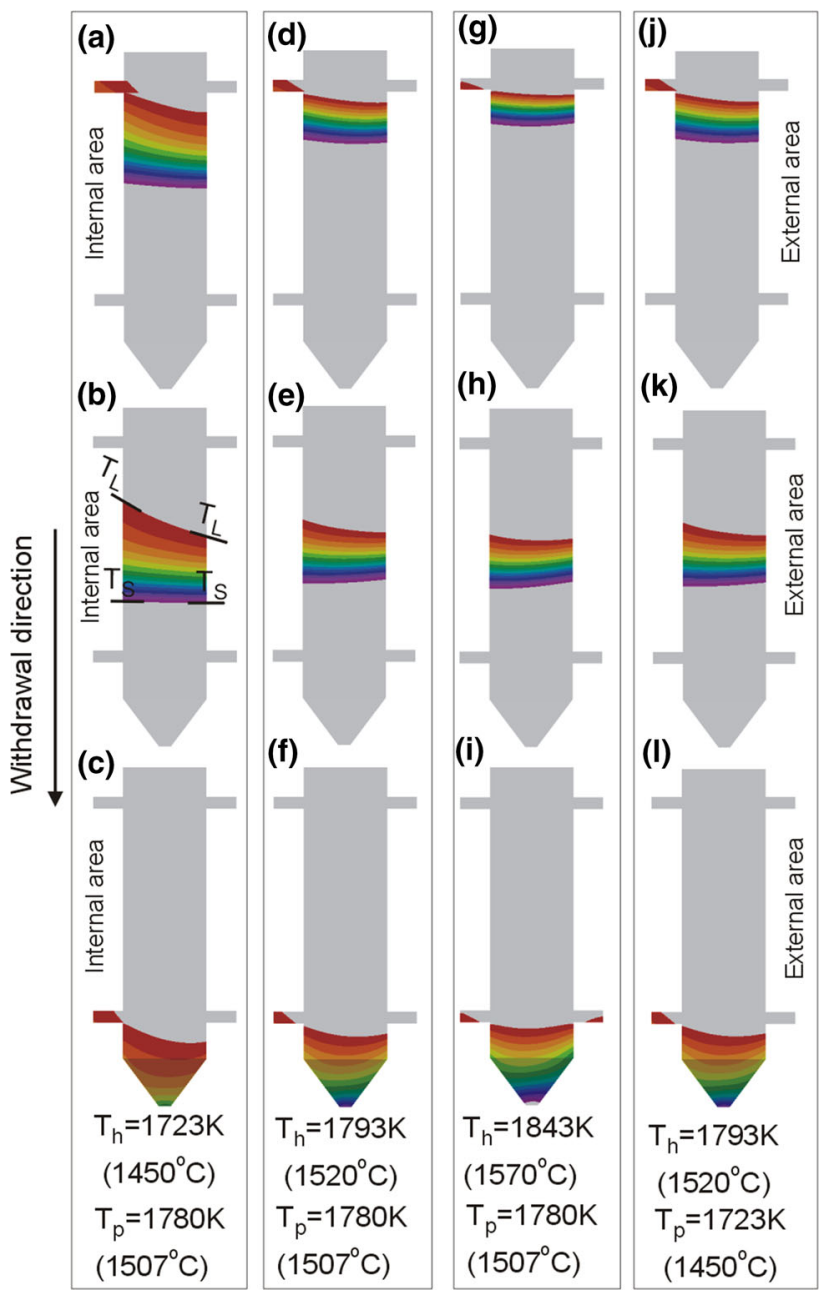

Fig. 17- Shape of the mushy zone along the height of blade 1 withdrawn at $3 \mathrm{~mm} / \mathrm{min}$ velocity for various temperatures of furnace heaters $T_{\mathrm{h}}$ and pouring temperature $T_{\mathrm{p}}$ : $(a$ through $c) T_{\mathrm{h}}=1723 \mathrm{~K}$ $\left(1450{ }^{\circ} \mathrm{C}\right), \quad T_{\mathrm{p}}=1780 \mathrm{~K}\left(1507^{\circ} \mathrm{C}\right) ; \quad(d$ through $f) T_{\mathrm{h}}=1793 \mathrm{~K}$ $\left(1520^{\circ} \mathrm{C}\right), \quad T_{\mathrm{p}}=1780 \mathrm{~K}\left(1507^{\circ} \mathrm{C}\right) ; \quad(g$ through $i) T_{\mathrm{h}}=1843 \mathrm{~K}$ $\left(1570{ }^{\circ} \mathrm{C}\right), T_{\mathrm{p}}=1780 \mathrm{~K}\left(1507^{\circ} \mathrm{C}\right)$ and $(j$ through $l) T_{\mathrm{h}}=1793 \mathrm{~K}$ $\left(1520^{\circ} \mathrm{C}\right), T_{\mathrm{p}}=1723 \mathrm{~K}\left(1450{ }^{\circ} \mathrm{C}\right) . T_{\mathrm{L}}, T_{\mathrm{S}}$ are the liquidus and solidus isotherm, respectively.

\section{Shape of the liquidus isotherm}

The shape of the liquidus isotherm and height of the mushy zone were determined along the length of blade 2 withdrawn at velocities of 1,3 and $5 \mathrm{~mm} / \mathrm{min}$ (Figure 16). It was assumed that the mushy zone in the solidifying casting was located between the liquidus and solidus isotherms. The connection between the continuator and root is characterized by a concave profile of the liquidus isotherm. The increase of withdrawal velocity results in the rise of its curvature in the external area of the root (Figures 16(c), (f) and (i)). Hence, in the first instance, the liquidus is reached in the internal area and afterwards in the external region (at the end of lower platform) for the withdrawal velocity of 1,3 and $5 \mathrm{~mm} / \mathrm{min}$. The decrease of casting thickness (airfoil of blade) also results in the reduction of the curvature degree of the liquidus isotherm. It attains a near flat shape in the area located $10 \mathrm{~mm}$ from the lower platform. With increasing distance from the lower 

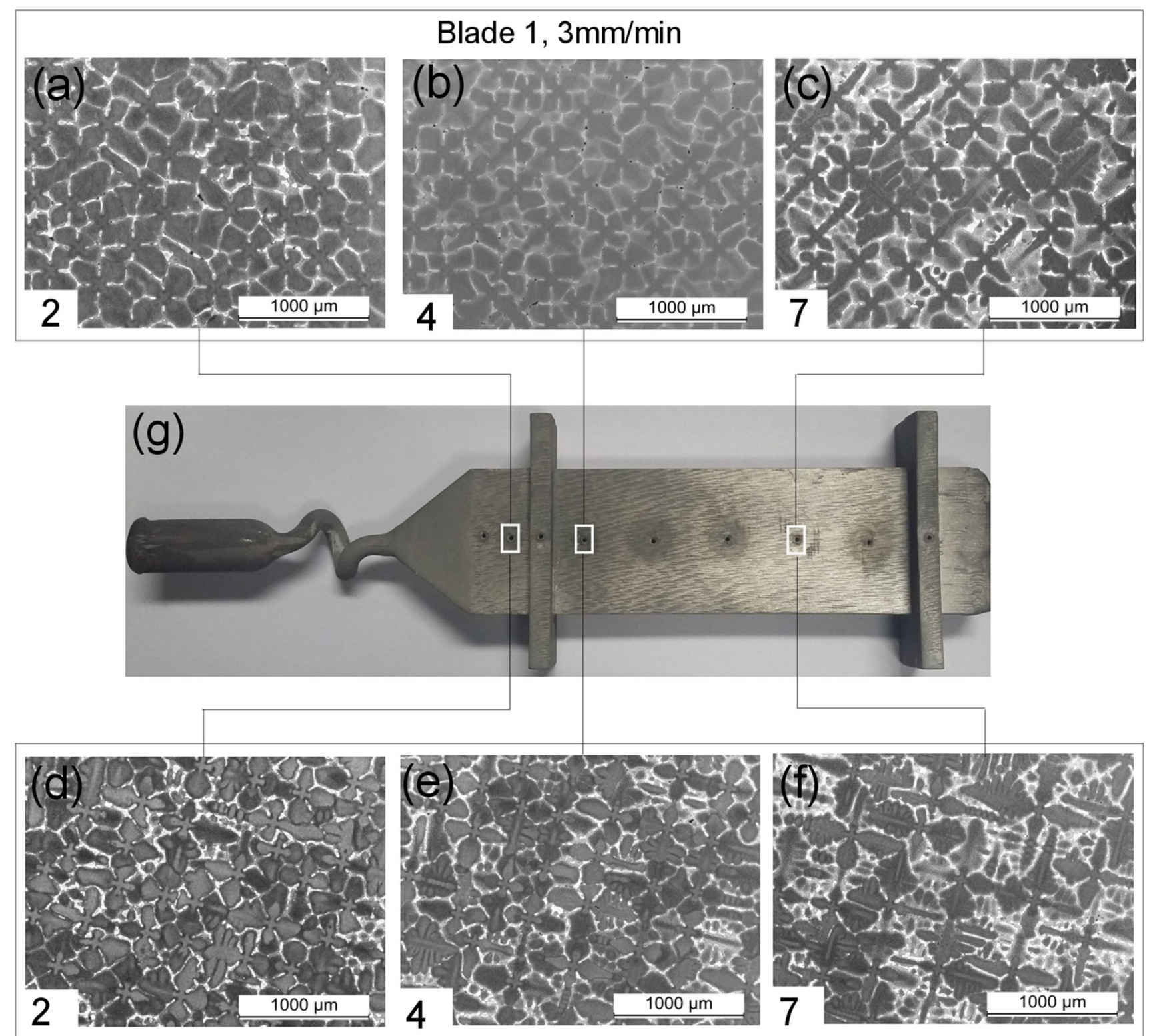

Blade 2, 5mm/min

Fig. 18-Exemplary dendritic microstructure of blade cross section at distances of $29(a, d), 48(b, e)$ and 99 mm $(c, f)$ from the casting base. Casting was withdrawn at velocities of 3 (a through c) and $5 \mathrm{~mm} / \mathrm{min}$ (d through $\mathrm{f}$ ). Starter, selector and blade with marked temperature measurement points $(g)$.

platform, the profile of the liquidus isotherm in the airfoil changes as well (Figures 16(b), (e) and (h)). The withdrawal velocity affects the shape of the liquidus isotherm to a greater extent in the external area of the airfoil along the casting height. For withdrawal velocities of 1 and $3 \mathrm{~mm} / \mathrm{min}$, the liquidus isotherm is inclined toward the middle of the airfoil (Figures 16(b) and (e)). The increase of velocity from 3 up to $5 \mathrm{~mm} / \mathrm{min}$ brings about the change of inclination direction toward the external edge of the airfoil (Figure 16(h)). In the upper platform, the liquidus was always reached first in the internal area, independently of the withdrawal velocity of casting (Figures 16(a), (d) and (g)). The inclination of the liquidus isotherm toward the internal edge made the external area of the upper platform solidify at the end of the process. It was found that the height of the mushy zone depended on the withdrawal velocity, casting thickness and distance from the casting base. The increase of the withdrawal velocity led to a rise in the height of the mushy zone (Figure 16). For withdrawal velocities of 1 and $3 \mathrm{~mm} / \mathrm{min}$, the height of the mushy zone in the root was larger than that in the blade airfoil (Figures 16(b), (c), (e) and (f)). However, the mushy zone in the root was lower than in the blade airfoil at the withdrawal velocity of $5 \mathrm{~mm} / \mathrm{min}$ (Figures 16(h) and (i)). 


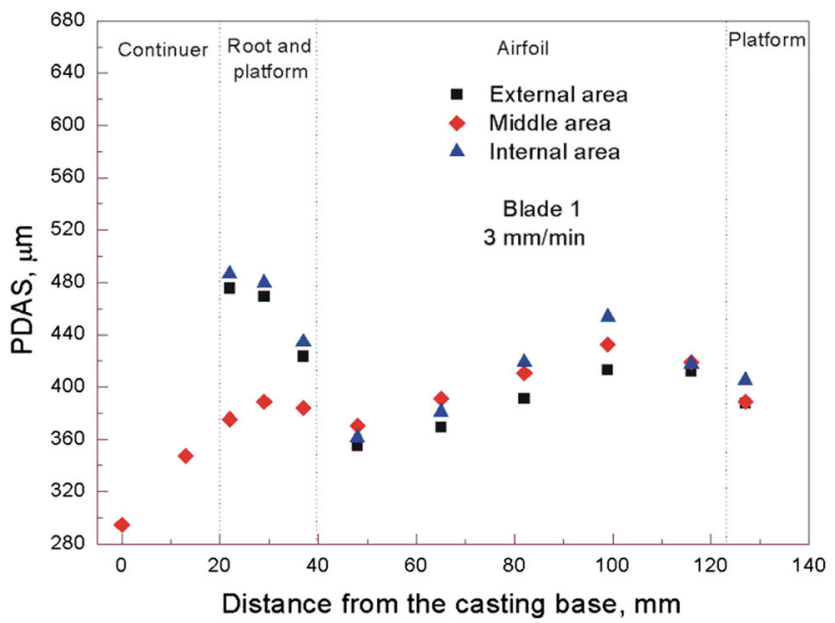

(a)

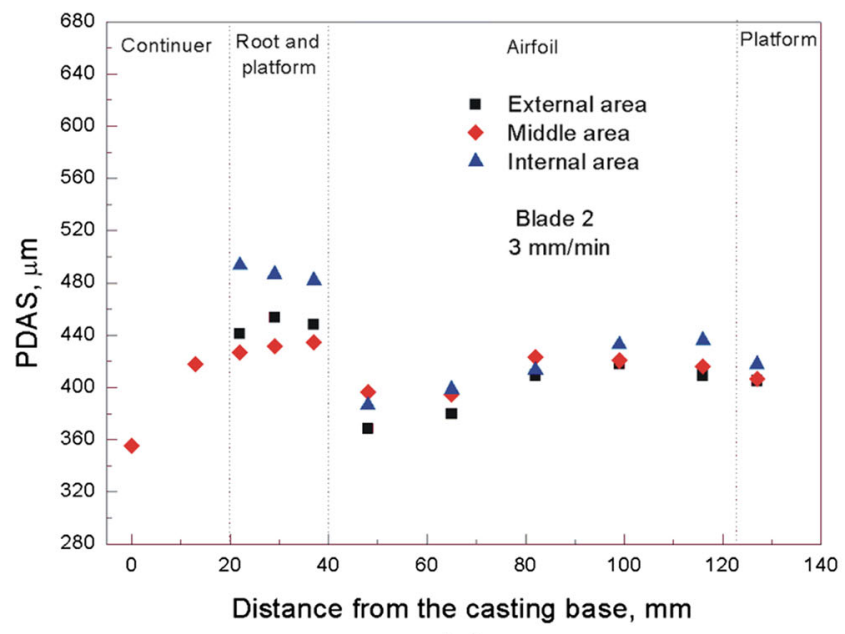

(c)

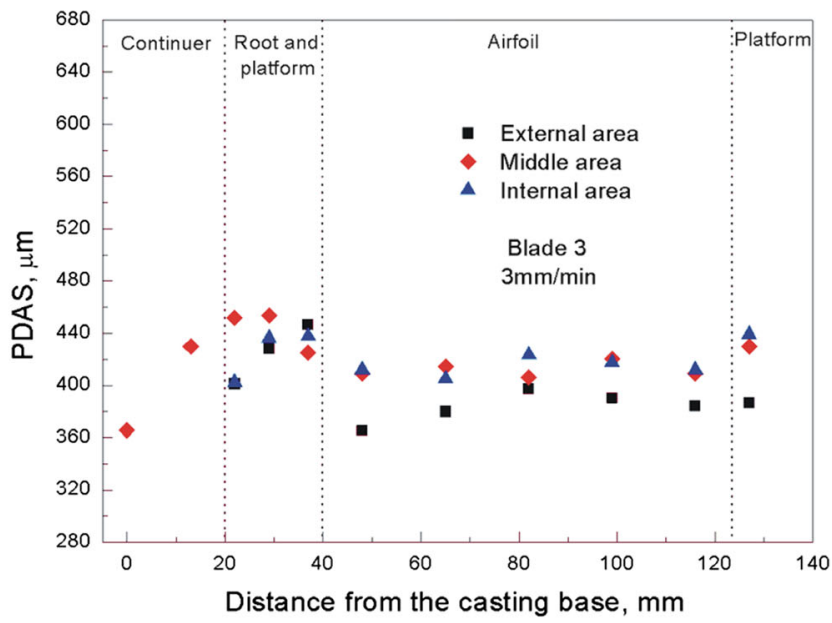

(b)

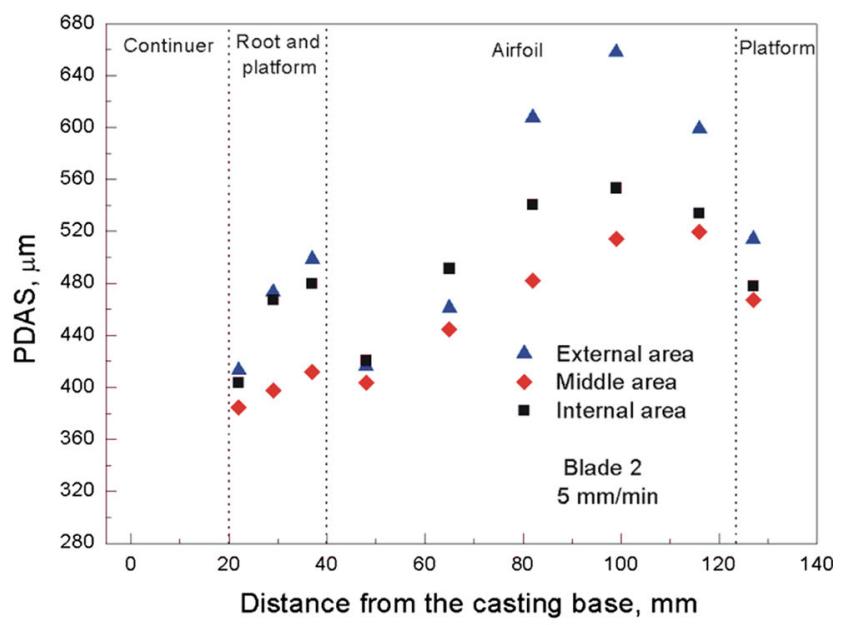

(d)

Fig. 19-Primary dendrite arm spacing in external, middle and internal areas of blades $1(a), 2(c, d)$ and $3(b)$ as well as along the casting height. The blades withdrawn at velocities of 3 (a through c) and 5 (d) $\mathrm{mm} / \mathrm{min}$.

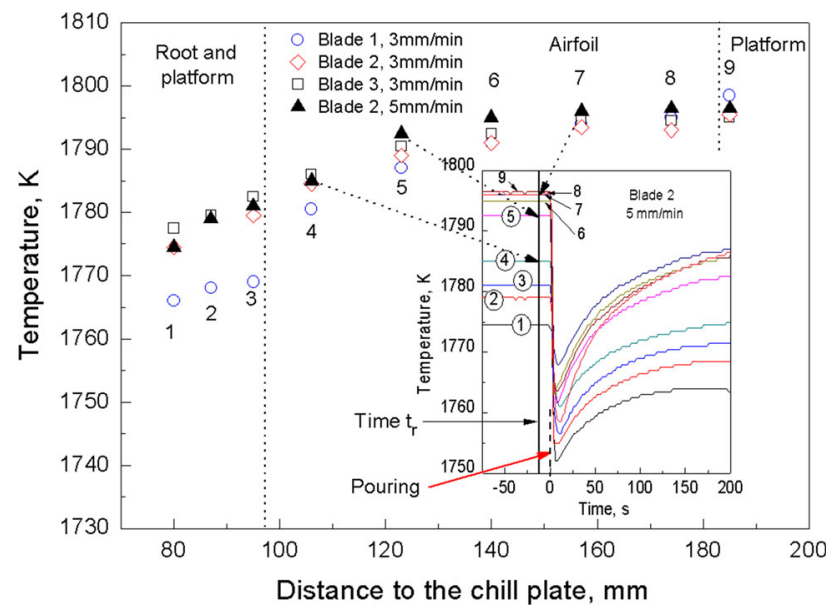

Fig. 20-Temperature distribution along the height of the mold cavity (before pouring) depending on the distance from the chill plate. The small graph shows the way to determine the values of temperature for the time $t_{\mathrm{r}}$ before pouring the alloy into the mold (blade 2), which then was withdrawn at a velocity of $5 \mathrm{~mm} / \mathrm{min}$.
The profile of the liquidus isotherm and height of the mushy zone were determined along the height of blade 1 at withdrawal velocity $3 \mathrm{~mm} / \mathrm{min}$ depending on different values of heater temperature $T_{\mathrm{h}}$ and pouring temperature $T_{\mathrm{p}}$ (Figure 17). It was established that the temperature of heaters (Figures 17(a) through (i)) intensively influenced the shape of the mushy zone compared with the pouring temperature (Figures 17(j) through (1)). The decrease of temperature $T_{\mathrm{h}}=1723 \mathrm{~K}\left(1450{ }^{\circ} \mathrm{C}\right)$ results in the increase of the curvature of the liquidus isotherm and the height of the mushy zone (Figures 17(a) through (c)). Therefore, the internal area of the upper and lower platform reaches the liquidus temperature earlier than the external area (Figures 17(a) and (c)). If the heater temperature is $1843 \mathrm{~K}\left(1570{ }^{\circ} \mathrm{C}\right)$, the curvature of the liquidus isotherm diminishes; it attains a near flat profile in the lower and upper platform and airfoil (Figures 17(g) through (i)). The height of the mushy zone also decreases with an increasing $T_{\mathrm{h}}$ value. 


\section{Microstructure}

Primary dendrite arm spacing (PDAS) characterizes the dendritic microstructure of single-crystal castings (Figure 18). It was determined in the internal, middle and external areas of the blade cross section at different distances from its base (Figure 19). PDAS changed along the height of the middle area of the blade and depended on the root thickness (Figures 19(a) through (c)). The lowest value of approximately 300,350 and $370 \mu \mathrm{m}$ was reached in the area of connection between the selector and continuer for blade 1, 2 and 3, respectively (Figures 19(a) through (c)). Along the continuer, PDAS increases intensively with the rise of distance from the blade base and reaches its maximum value in the root and lower platform. Above the platform of blade 1 and 2, PDAS diminishes again down to the minimum value of approximately $370 \mu \mathrm{m}$ in the airfoil (Figures 19(a) and (c)). The increase of distance from the platform (approximately $100 \mathrm{~mm}$ from the base) results in the rise of PDAS until the maximum value in the airfoil is attained. Afterwards, it lowers in the remaining part of blade (Figures 19(a) and (c)). Simultaneously, it was established that PDAS changed little in the airfoil along the height of blade 3 with constant thickness (Figure 19(b)), while for the root the value was similar to or greater than that for the remaining blades.

It was determined that PDAS changed in the blade with the increase of distance from the heaters toward the central rod (Figure 19). In the airfoil, PDAS attained the highest value in the internal and decreased in the middle and external areas of casting. Moreover, its value in the root was higher for both the external and internal areas than in the middle part. Additionally, that difference increased with increasing root thickness (Figures 19(a) and (c)) or withdrawal velocity of casting (Figure 19(d)). Increasing the withdrawal velocity of blade 2 from 3 up to $5 \mathrm{~mm} / \mathrm{min}$ did not significantly change the PDAS inside the root in both the middle area and near the edge (Figures 19(c) and (d)). On the other hand, a large increase of the PDAS value was detected in the upper part of the airfoil, especially in the internal areas of the blade (Figure 19(d)). At this height, the PDAS approached the maximum value in the areas closer to the blade edge than in the middle part, unlike for the withdrawal velocity of $3 \mathrm{~mm} / \mathrm{min}$ (Figures 19(a) through (d)).

\section{DISCUSSION}

\section{A. Temperature Distribution}

The analysis of measurement results showed that the temperature distribution was not homogeneous along the mold height during the heating process and before pouring the alloy into the cavity (Figure 20). At the height of $80 \mathrm{~mm}$ from the chill plate, the average temperature was approximately $1775 \mathrm{~K}\left(1502{ }^{\circ} \mathrm{C}\right)$ for blade 2 and 3 and was lower than the heater temperature, which was $1793 \mathrm{~K}\left(1520{ }^{\circ} \mathrm{C}\right)$. According to expectations, the temperature increased with increasing distance from the chill plate. It was established that at the height of approximately $130 \mathrm{~mm}$ (above the lower platform) it started to stabilize up to $1793 \mathrm{~K}\left(1520^{\circ} \mathrm{C}\right)$, although a different distribution of temperature was observed for blade 1. The temperature was lower in the root area compared with the remaining part. Above the lower platform, the temperature increased and gained similar values to those for blades 2 and 3 . The lower temperature in the root area of blade 1 is a result of the influence of the chill plate on the mold surface, which is located below the lower platform. The platform of blade 1 has a significantly larger surface area compared with blade 2 and 3, and it functions as a thermal baffle. Such a location of the lower and upper platform limits the heating process of the mold areas below. Szeliga et al. ${ }^{[26]}$ reported that the application of an internal radiation baffle below the platform considerably affected the temperature distribution in this area. The area below the lower platform was cooled through the interaction of the chill rings, chill plate and to a lesser extent heaters. Hence, the reduction of platform size results in the intensification of the heater effect and a rise in temperature in the root area, particularly in the mold with blade 3 (Figure 20).

A significant decrease of temperature, measured by thermocouples, was detected during the pouring process (Figure 6). The characteristic peaks of the plot resulted from the contact of the ceramic shell mold and liquid alloy at relatively low temperature (Figure 20). Despite the fact that the liquid alloy filling the mold was overheated to the temperature of approximately $1794 \mathrm{~K}$ $\left(1520^{\circ} \mathrm{C}\right)$, a change in its temperature was detected. Additionally, the liquid alloy temperature decreased along the mold length and reached its minimum value in the root area for blades 2 and 3 (Figures 6(b) through (d) and 20). Due to the interaction of the liquid alloy with the mold, its temperature diminished by approximately $35^{\circ} \mathrm{C}$ (blade 2, Figure 6(c)), which was significantly lower than during the pouring process. Large differences in the temperature of the alloy flowing into the mold (controlled with pyrometer) could be caused by variable conditions of the pouring process. The duration of the pouring process, deflection rate of the crucible,

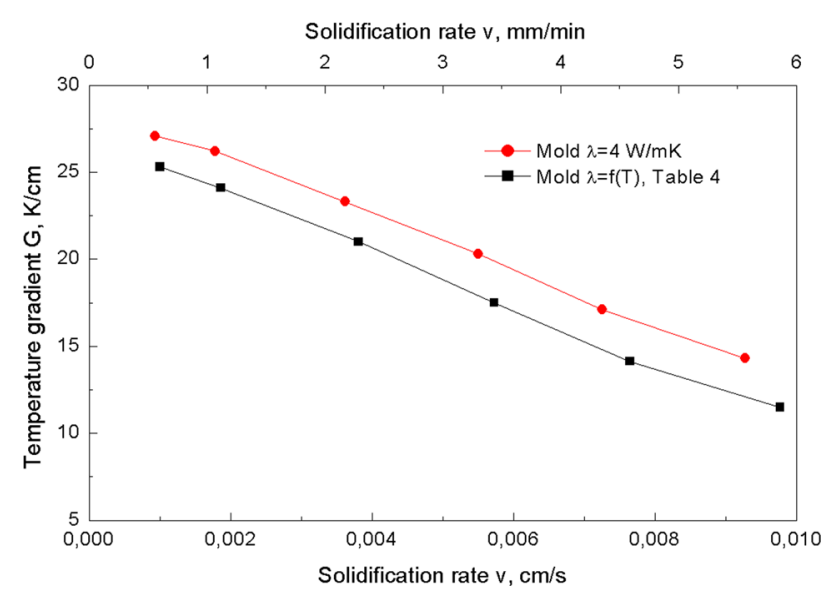

Fig. 21-Temperature gradient depending on the solidification rate of casting and thermal conductivity of the ceramic shell mold. 
method of directing the liquid metal stream into the mold and control of the alloy temperature before pouring were important factors as well.

The liquid metal that flows into the mold gets heated up because of its thermal interaction (Figure 6). It attains the same temperature value as the ceramic shell mold (before solidification) when the liquidus isotherm is located below the blade base in the selector and starter area. Hence, a pouring temperature between $1723 \mathrm{~K}$ and $1843 \mathrm{~K}\left(1450{ }^{\circ} \mathrm{C}\right.$ and $\left.1570^{\circ} \mathrm{C}\right)$ does not cause a large change of the solidification parameters in the casting (Figures 14(c) and (d)). However, its value significantly affects the solidification of the starter and the competitive dendrite growth as well as the formation of the columnar grain. ${ }^{[27]}$ The increase of pouring temperature results in the improvement of single-crystal material quality through the reduction of the misorientation angle between the [001] direction and symmetry axis. ${ }^{[27]}$

Good agreement between the actual and simulated values of the temperature distribution was found. The analysis of cooling curves (Figure 7) showed that the largest differences between the measured and simulated values occurred in the temperature range between the liquidus and solidus when solidification took place. In that range, the shape of cooling curves depended mainly on the thermophysical properties of the CMSX-4 alloy, namely the solid fraction, thermal conductivity, density and enthalpy ${ }^{[28]}$ (Table III). The values of those quantities and the temperature of solidification start and finish depending on the cooling rate of the casting. They are usually determined experimentally for selected cooling rates similar to the average cooling rate of the casting and entered in the database of the simulation software. However, the cooling rate of the blade is not uniform because of its complex shape. It results in variable fitting of the measured and predicted cooling curves (Figure 7). The lowest match of the temperature values was observed in the upper part of the blade especially for a withdrawal rate of $5 \mathrm{~mm} / \mathrm{min}$ (points 6-9). Besides the properties of the alloy, also the thermal conductivity, wall thickness

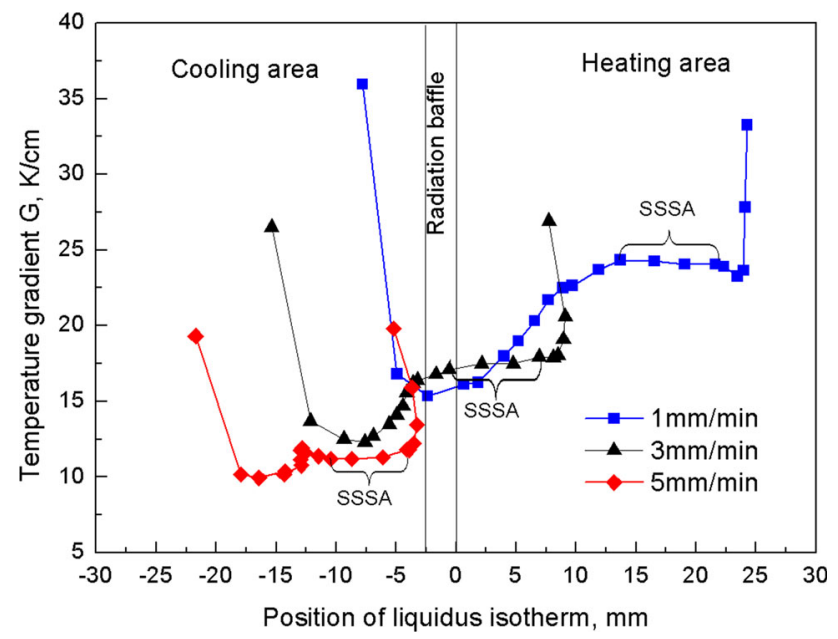

Fig. 22-Temperature gradient depending on the location of the liquidus isotherm relative to the radiation baffle for casting with constant thickness (blade 3). Blade withdrawn at velocities of 1,3 and $5 \mathrm{~mm} / \mathrm{min}$. SSSA denotes steady-state solidification area. and emissivity of the mold have a great impact on the cooling rate and consequently on the solidification of casting. ${ }^{[29]}$ The layer of the mold generated by the software can be of different thicknesses compared with the real mold especially in the regions where the cross section of the mold changes, whereas the thermal conductivity of the mold depends on the materials used for its preparation. Emissivity of the mold may also change during the process because of carbon absorption from graphite heaters and furnace insulation.

\section{B. Effect of Blade Shape on Solidification Parameters}

The analysis of the obtained research results allowed establishing that the geometry of casting determined the position of the liquidus isotherm $L$ and temperature gradient as well as the solidification rate (Figures 9 and 11). The increase of root and platform thicknesses led to the shift of the liquidus isotherm toward the heating area. However, that effect was most noticeable in the root and platform area of blade 1 . The large surface of the lower platform resulted in the creation of a radiation baffle, and it intensified the interaction between the chill plate and area of the continuer and root. Hence, the heat extraction from that area referred more to blade 2 and 3 , for which the platform was smaller. No stabilization of distance $L$ was also observed along the height of blade 3 despite its constant thickness. The instability of the location of the liquidus isotherm relative to the thermal baffle was probably caused by the geometry of the ceramic shell mold and continuous changing of conditions of heat transfer between the chill ring and mold surface during its withdrawal. The phenomenon could result in variable conditions of solidification in the bottom, middle and upper part of casting despite its constant cross section. ${ }^{[30]}$

An unfavorable and gradual increase of the solidification rate was achieved in the area from the bottom platform to approximately half the height of airfoil blade 1 and 2, especially at a withdrawal $5 \mathrm{~mm} / \mathrm{min}$ velocity (Figures 9(b) and 12(b)). Above that area, it dropped intensively. It was caused by the location of liquidus isotherm in the platform/airfoil area (point 4), which was significantly more distant from the radiation baffle than in the root (Figure 13). Hence, its gradual movement along the blade height was decelerated, and it was shifted toward the cooling area as a result of the effect of the large root volume. Therefore, the liquidus isotherm in the blade airfoil was strongly shifted toward the heating area during further stages of the solidification. The distance from the radiation baffle was gradually decreased to maintain the stabilization of the solidification process and to obtain the assumed conditions of heat transfer for a given withdrawal velocity.

\section{Effect of Withdrawal Velocity on Temperature Gradient}

It was found that the minimum temperature gradient value corresponded to the maximum solidification rate (Figures 9 and 12). The reduction of the solidification rate led to an increase of temperature gradient in 
castings, which were withdrawn at velocities 1 and $5 \mathrm{~mm} / \mathrm{min}$. For the Bridgman method, the predicted temperature gradient reached its maximum $G=40 \mathrm{~K} /$ $\mathrm{mm}$ for a withdrawal velocity of approximately $4 \mathrm{~mm} /$ min of the rod. ${ }^{[31]}$ Miller and Pollock ${ }^{[16]}$ obtained $G=22 \mathrm{~K} / \mathrm{mm}$ for the withdrawal velocity of the blade of approximately $2 \mathrm{~mm} / \mathrm{min}$. The temperature gradient started to decrease above and below the critical withdrawal velocity. ${ }^{[16,31]}$ Raising the temperature gradient (LMC method) led to obtaining a higher critical mold withdrawal velocity. Hence, numerical simulation of the solidification parameters ( $G$ and $v)$, depending on the withdrawal velocity of blade 3 , was performed to establish the maximum temperature gradient (Figure 21). For this purpose, the area where the temperature gradient and solidification rate changed slightly along blade 3 was established. This area was situated in the distance range from approximately $60 \mathrm{~mm}$ to $130 \mathrm{~mm}$ from the base, and it was called the steady-state solidification area (SSSA). The formation of the SSSA in the $12 \mathrm{~mm}$-diameter rod, solidified by the Bridgman method, was also detected approximately $40 \mathrm{~mm}$ from the chill plate. ${ }^{[9]}$ Franke et al. ${ }^{[4]}$ showed that the SSSA appeared in the $36 \mathrm{~mm}$-diameter rod at a height of approximately $50 \mathrm{~mm}$ from the casting base withdrawn at the velocity of $3 \mathrm{~mm} / \mathrm{min}$. The SSSA at a rate of $9 \mathrm{~mm} / \mathrm{min}$ was not observed. Therefore, the temperature gradient and solidification rate were determined at a casting height of $100 \mathrm{~mm}$, where the SSSA occurs. It was established that the temperature gradient continuously increased with a decrease of solidification rate, even down to $0.5 \mathrm{~mm} / \mathrm{min}$ (Figure 21). No re-drop of the temperature gradient was observed contrary to what was reported in References 16, 31 .

Fitzgerald and Singer ${ }^{[32]}$ suggested that the temperature gradient of casting could be made larger by the increase of mold thermal conductivity. Its effect on the temperature gradient depending on the solidification rate was checked (Figure 21). In the simulations performed it was assumed the thermal conductivity of the mold is the function of temperature (Table IV). The results obtained were compared with those obtained for the constant value $\lambda=4 \mathrm{~W} / \mathrm{mK}$. Its increase resulted in a rise of temperature gradient by approximately $4 \mathrm{~K} / \mathrm{cm}$ (Figure 21).

The obtained results depicted in Figures 9 through 13 and those reported by References 16, 31 indicate that, apart from the solidification rate and casting shape, the location of the liquidus isotherm regarding the radiation baffle can influence the temperature gradient as well. It was found that for the withdrawal velocity of $1 \mathrm{~mm} / \mathrm{min}$ and liquidus isotherm located above the thermal baffle (Figure 13), the temperature gradient decreased (Figure 12(a)) in the $50-100 \mathrm{~mm}$ distance range from the casting base (blade 2). However, it became bigger for $5 \mathrm{~mm} / \mathrm{min}$ velocity when the liquidus isotherm was near the thermal baffle (Figure 12(a)). Hence, an assumption could be made that the location of the liquidus isotherm in the area of the radiation baffle might provide the maximum temperature gradient according to Reference 31. However, the complex geometry of the blade did not allow establishing unambiguously which of the listed factors had a decisive effect on the temperature gradient. Therefore, the temperature gradient in blade 3 with a constant thickness was determined depending on the location of the liquidus isotherm relative to the radiation baffle (Figure 22). It was established that the temperature gradient diminished in the steady-state solidification area (SSSA) despite the continuous change of the liquidus isotherm location regarding the radiation baffle. The SSSA formed at a distance of approximately $65 \mathrm{~mm}$ from the casting base and the initial stage occurred below and above the radiation baffle depending on the withdrawal velocity of casting. Due to the continuous section change of the casting continuer, there was no steady-state solidification process at a distance $<65 \mathrm{~mm}$ from the casting base. The initial stage of the stabilization of the temperature gradient in the casting corresponded to the location of the liquidus isotherm at a distance of approximately $-13,-0.6$ and $10.5 \mathrm{~mm}$ from the radiation baffle at withdrawal velocities of 5, 3 and $1 \mathrm{~mm} / \mathrm{min}$, respectively. At that point, it attained the value of approximately $24.3,17.5$ and $11.3 \mathrm{~K} / \mathrm{cm}$ for withdrawal velocities of 1,3 and $5 \mathrm{~mm} / \mathrm{min}$, respectively. Hence, it was established that a further shift of the liquidus isotherm in the SSSA toward the heating area did not cause either an increase or reduction of the temperature gradient.

\section{Shape of the Liquidus Isotherm}

The liquidus isotherm shape and value of the temperature gradient affect the microstructure and formation of defects in directionally solidified casting blades made of nickel-based superalloy. ${ }^{[10,11,33]}$ Szeliga et al. ${ }^{[26]}$ determined that a too concave shape of the mushy zone in the platform results in a high value of undercooling and the formation of a strain grain. Therefore, control of the mushy zone shape and temperature gradient along the height of the blade is very important during the solidification of blade castings. Thus, the objective was to provide the highest temperature gradient and shape of the mushy zone, which is possibly the closest to flat, by modifying the design of the mold ${ }^{[10]}$ or using different techniques. $^{[34]}$

It was determined that the shape and height of the mushy zone can be affected by the location of the liquidus isotherm regarding the radiation baffle and temperature gradient (Figures 16 and 17). The height of mushy zone $H$ is related to temperature gradient $G$ and the difference between the liquidus and solidus temperature $\Delta T_{1-\mathrm{s}}$ according to relation $H=\Delta T_{1-\mathrm{s}} / G$. Hence, the increase of temperature gradient $G$ in the mushy zone causes a reduction of its height. The increase of $G$ results in a decrease of temperature gradient $G_{\mathrm{x}}$ toward the direction perpendicular to the symmetry axis of the blade. It also reduces the curvature of the liquidus isotherm. It was established that the liquidus isotherm had the largest curvature if the mushy zone was located mainly above the radiation baffle in the heating area (Figure 15) for a heater temperature of $1723 \mathrm{~K}$ $\left(1450{ }^{\circ} \mathrm{C}\right)$ (Figures 17(a), (b) and (c)). The curvature diminished if the isotherm was located slightly below the 


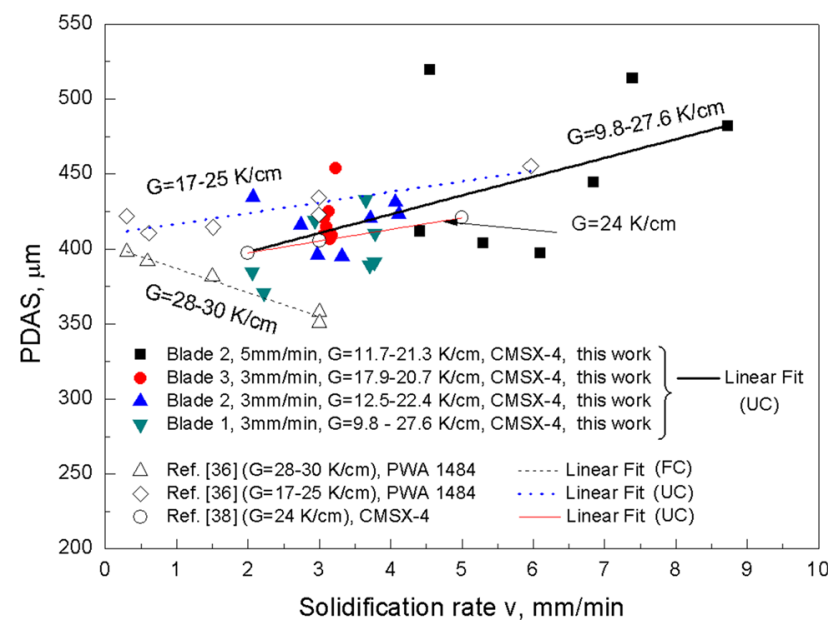

Fig. 23-Influence of solidification rate and temperature gradient on PDAS. FC and UC are favorable and unfavorable conditions of solidification, respectively.

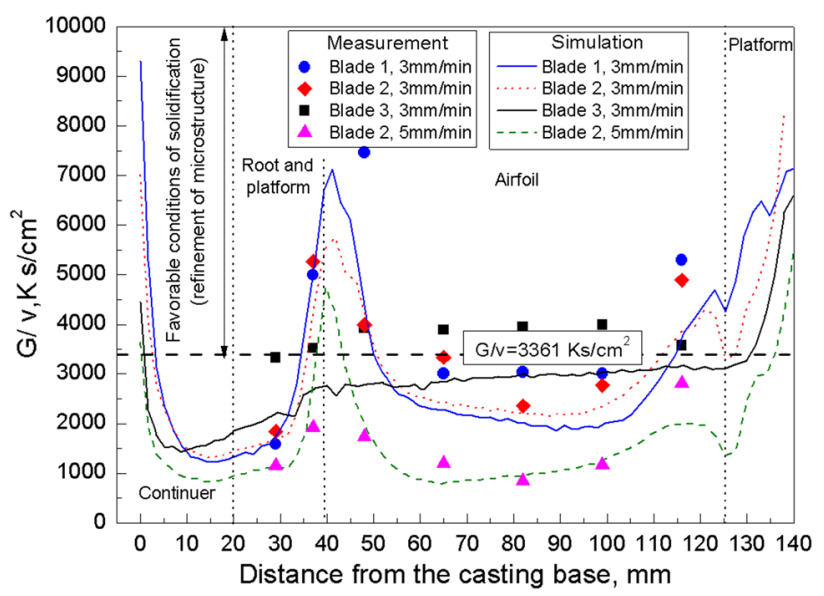

Fig. 24-Value of $G / v$ in the function of distance from the base of blade 1, 2 and 3, withdrawn at velocities of 3 and $5 \mathrm{~mm} / \mathrm{min}$. The limit value of $G / v=3361 \mathrm{Ks} / \mathrm{cm}^{2}$ above which the favorable conditions of solidification occur and PDAS decrease (refinement of microstructure).

radiation baffle and the mushy zone reached the level of thermal insulation (placed on a chill ring) (Figures 17(g), (h) and (i)).

\section{E. Effect of Solidification Parameters on the Microstructure}

On the basis of the conducted microscopic observations, it has been established that the distribution of PDAS changes along the length of blades. Kurz and Fisher ${ }^{[35]}$ developed an analytical relation between the solidification parameters and the primary dendrite arm spacing (PDAS) for the steady-state solidification process:

$$
\mathrm{PDAS}=K_{1} G^{-0.5} v^{-0.25}
$$

where $K_{1}$ is the material constant of the alloy, $G$ is the temperature gradient, and $v$ is the solidification rate. The analysis of this equation shows that the PDAS diminishes with the increase of temperature gradient and solidification rate. Such a relation between the solidification parameters and the refinement of the dendritic structure for directionally solidified nickel alloys was confirmed in Reference 7, 36. Refining of the PDAS in a single-crystal casting blade is favorable because it reduces both the duration of heat treatment and pore size as well as improves the fatigue life. ${ }^{[37]}$ Therefore, according to those results, the increase of the solidification rate should diminish the PDAS provided the temperature gradient is constant. However, during this research, an unfavorable rise of the PDAS, mainly for a withdrawal velocity of $5 \mathrm{~mm} / \mathrm{min}$, was detected together with an increase of the solidification rate (Figure 23). Li and Overfelt ${ }^{[36]}$ observed a similar relationship during directional solidification of PWA $1484 \mathrm{Ni}$-based superalloy but only for the temperature gradient range of $G=17$ to $25 \mathrm{~K} / \mathrm{cm}$ and solidification rate of 3 and $6 \mathrm{~mm} / \mathrm{min}$. The reduction of the temperature gradient to $G=12$ to $15 \mathrm{~K} / \mathrm{cm}$ $(v=6 \mathrm{~mm} / \mathrm{min})$ resulted in a greater increase of PDAS. ${ }^{[36]}$ Montakhab et al. ${ }^{[38]}$ reported the increase of PDAS with an increasing solidification rate of CMSX-4 casting, manufactured using standard and equipped with a submerged baffle Bridgman method and applying a constant temperature gradient of $24 \mathrm{~K} /$ $\mathrm{cm}$ as well as solidification rate of $5 \mathrm{~mm} / \mathrm{min}$. For the withdrawal velocity of $5 \mathrm{~mm} / \mathrm{min}$, the highest temperature gradient achieved in the analyzed blades and in Reference 38 was equal to $G=24 \mathrm{~K} / \mathrm{cm}$. In contrast, when the temperature gradient was greater than $G=28 \mathrm{~K} / \mathrm{cm}$, the PDAS decreased favorably with increasing solidification rate. ${ }^{[36]}$

Based on the obtained results, it can be assumed that the favorable refinement of the microstructure of single-crystal casting, manufactured using the Bridgman method at a solidification rate of $5 \mathrm{~mm} / \mathrm{min}$, can be possible when $G>28 \mathrm{~K} / \mathrm{cm}$. Hence, the limit value of $G / v=3361 \mathrm{Ks} / \mathrm{cm}^{2}$ was determined above which the PDAS decreased. It should be considered that that temperature gradient also corresponded to a certain limit of the solidification rate when the PDAS was the smallest. In the LMC, ${ }^{[30]} \mathrm{GCC},{ }^{[39]} \mathrm{FCB}^{[40]}$ and DWDS $^{[41]}$ methods, the continuous refinement of the microstructure was observed when the withdrawal velocity of mold increased. For example, in the LMC method, the limit rate was $12.7 \mathrm{~mm} / \mathrm{min}$, because heat extraction from the surface of the mold to the coolant and temperature gradient was higher than in the Bridgman method. ${ }^{[30]}$

To determine the relation between the PDAS and solidification parameters, the $G / v$ value was established along the blade height in its middle area. Figure 24 shows the $G / v$ depending on the distance from the casting base together with the calculated limit of $G / v=3361 \mathrm{Ks} / \mathrm{cm}^{2}$. In this way, the favorable conditions of solidification (refinement of microstructure) in the blade were determined taking into account the 
temperature gradient and solidification rate. It was determined that blade 3 was located in favorable solidification conditions in spite of blade 1 and 2, which appeared only partially in that region (Figure 24). The highest refinement of the microstructure and the lowest PDAS were observed in the area of transition of the root into the airfoil of blades 1 and 2 withdrawn at $3 \mathrm{~mm} /$ min velocity (Figures 19(a) and (c)). In the area (distance of $40 \mathrm{~mm}$ from the casting base), the solidification rate was the smallest (approximately $2 \mathrm{~mm} / \mathrm{min}$ ), while the temperature gradient reached $G=19 \mathrm{~K} / \mathrm{cm}$ (Figure 9); hence, the $G / v$ equaled $5700 \mathrm{Ks} / \mathrm{cm}^{2}$. The PDAS also decreased at the top part of the airfoil for a distance from the blade base $>100 \mathrm{~mm}$ (Figures 19(a) and (c)). In place of the blade (point 8), the solidification rate decreased to approximately $2.8 \mathrm{~mm} / \mathrm{min}$, while the temperature gradient increased up to approximately $G=24 \mathrm{~K} / \mathrm{cm}\left(G / v=5142 \mathrm{Ks} / \mathrm{cm}^{2}\right)$ (Figure 9). For a withdrawal velocity of $5 \mathrm{~mm} / \mathrm{min}$, the $G / v$ value was too low to promote a continuous increase of PDAS (unfavorable solidification conditions).

\section{CONCLUSIONS}

Based on the analysis of research results, the following conclusions were drawn:

1. The solidification parameters were established along the blade height with variable thicknesses of the root and platforms. The increase of root thickness resulted in the rise of inhomogeneity of the temperature gradient and solidification rate as well as unsteady-state solidification along the whole blade length in spite of the temperature gradient, which changed little in the blade with constant thickness. The steady-state solidification was established for the range between 65 and $130 \mathrm{~mm}$.

2. It was determined that there was no universal location of the liquidus isotherm relative to the radiation baffle, which ensured obtaining the maximum temperature gradient in the steady-state solidification area of casting withdrawn at different velocities. The shift of the liquidus isotherm in the casting above the radiation baffle resulted in neither an increase nor drop of the temperature gradient.

3. The solidification rate varied along the blade height compared with the withdrawal velocity of the mold. Their difference increased with increasing of the withdrawal velocity of the mold and the root thickness of the blade. The solidification rate reached its minimum value in the root and maximum value in the airfoil.

4. The temperature gradient increased with lowering of the solidification rate or thickness of casting. Hence, its lowest value was obtained in the root and airfoil of the blade.

5. The increase of heater temperature resulted in the rise of the temperature gradient, whereas the pouring temperature did not affect the solidification parameters in terms of thermal impact of the mold and rel- atively fast heating of the alloy to the same temperature.

6. The critical temperature gradient of $G=28 \mathrm{~K} / \mathrm{cm}$ was determined for the solidification rate of $5 \mathrm{~mm} /$ min above which the primary dendrite arm spacing (PDAS) decreased and refinement of microstructure might occur.

7. The primary dendrite arm spacing (PDAS) changed along the blade lengths in a similar manner to the solidification parameters (solidification rate and temperature gradient). The favorable refinement of the microstructure was obtained in the area of transition of the root into an airfoil and the top part of the blade where $G / v$ was higher than $3361 \mathrm{Ks} / \mathrm{cm}^{2}$. The highest PDAS was reached in the root and in the middle part of the airfoil, especially at a withdrawal velocity of $5 \mathrm{~mm} / \mathrm{min}$. The increase in root thickness and withdrawal velocity resulted in a rise of the PDAS in the external and internal areas of the blade. It caused an increase of its inhomogeneity along the casting height as well.

8. Particularly unfavorable conditions of the solidification process were observed in the middle part of the airfoil and root because of the lowest temperature gradient and highest primary dendrite arm spacing.

\section{ACKNOWLEDGMENT}

The article was written on the basis of research project (DEC-2013/09/N/ST8/02042) financed by the Polish National Science Centre.

\section{OPEN ACCESS}

This article is distributed under the terms of the Creative Commons Attribution 4.0 International License (http://creativecommons.org/licenses/by/4.0/), which permits unrestricted use, distribution, and reproduction in any medium, provided you give appropriate credit to the original author(s) and the source, provide a link to the Creative Commons license, and indicate if changes were made.

\section{REFERENCES}

1. R.C. Reed: The Superalloys Fundamentals and Applications, Cambridge University Press, Cambridge, 2006, pp. 1-18.

2. K. Kubiak, D. Szeliga, J. Sieniawski and A. Onyszko: in The Unidirectional Crystallization of Metals and Alloys (Turbine Blades), $2^{\text {nd }}$ ed., P. Rudolph, ed., Elsevier, Amsterdam, 2015, pp. 413-57.

3. G. Jarczyk and D. Szeliga: Giesserei-Praxis, 2013, vol. 11, pp. 46873.

4. M.M. Franke, R.M. Hilbinger, A. Lohmüller, and R.F. Singer: $J$. Mater. Process. Technol., 2013, vol. 213, pp. 2081-88.

5. X. Guo, H. Fu, and J. Sun: Metall. Mater. Trans. A, 1997, vol. 28A, pp. 997-1009.

6. F. Wang, D. Ma, S. Bogner, and A. Bührig-Polaczek: Metall. Mater. Trans. A, 2016, vol. 47A, pp. 2376-86. 
7. T.M. Pollock and W.H. Murphy: Metall. Mater. Trans. A, 1996, vol. 27A, pp. 1081-94.

8. J.D. Miller and T.M. Pollock: Acta Mater., 2014, vol. 78, pp. 23 36.

9. D. Szeliga, K. Kubiak, M. Motyka, and J. Sieniawski: Vacuum, 2016, vol. 131, pp. 327-42.

10. L. Qin, J. Shen, G. Yang, Q. Li, and Z. Shang: Mater. Des., 2017, vol. 116 , pp. $565-76$

11. R.E. Napolitano and R.J. Schaefer: J. Mater. Sci., 2000, vol. 35, pp. 1641-59.

12. J. Yu, Q. Xu, K. Cui, B. Liu, A. Kimatsuka, Y. Kuroki, and A. Hirata: J. Mater. Sci. Technol., 2007, vol. 23, pp. 47-54.

13. J. Li, S. Liu, and Z. Zhong: J. Mater. Sci. Technol., 2002, vol. 18, pp. 315-18.

14. D. Goldschmidt, U. Paul, and P.R. Sahm: Superalloys 1992, The Mineral Metals and Materials Society, Pittsburgh, 1992, pp. 15564.

15. M.M. ter Vehn, D. Dedecke, U. Paul, and P.R. Sahm: Superalloys 1996, The Mineral, Metals and Materials Society, Pittsburgh, 1996, pp. 471-80.

16. J.D. Miller and T.M. Pollock: Metall. Mater. Trans. A, 2012, vol. 43A, pp. 2414-25.

17. Y.S. Touloukian and D.P. DeWitt: Thermal Radiative Properties: Nonmetallic Solids, IFI/Plenum, New York, 1972, pp. 139-97.

18. B. Staniszewski: Heat Transfer, Warsaw, WNT, 1980, p. 413.

19. G. Neuer: Int. J. Thermophys., 1995, vol. 16, pp. 257-65.

20. K.C. Mills: Recommended Values of Thermophysical Properties for Selected Commercial Alloys, Woodhead Publishing, Cambridge, 2002, pp. 167-74.

21. L.A. Chapman: J. Mater. Sci., 2004, vol. 39, pp. 7229-36.

22. D. Szeliga, K. Kubiak, W. Ziaja, and R. Cygan: Int. J. Cast Met. Res., 2014, vol. 27, pp. 146-60.

23. Graphites for High-temperature Furnaces (Sigratherm), Guide of SGL Carbon Group, 2016.

24. P. Carter, D.C. Cox, C.A. Gandin, and R.C. Reed: Mater. Sci. Eng.: A, 2000, vol. 280, pp. 233-47.
25. F. Wang, D. Ma, S. Bogner, and A. Bührig-Polaczek: Metall. Mater. Trans. A, 2016, vol. 47A, pp. 3703-12.

26. D. Szeliga, K. Kubiak, and J. Sieniawski: J. Mater. Process. Technol., 2016, vol. 232, pp. 18-26.

27. S.F. Gao, L. Liu, N. Wang, X.B. Zhao, J. Zhang, and H.Z. Fu: Metall. Mater. Trans. A, 2012, vol. 43A, pp. 3767-75.

28. X.L. Yang, P.D. Lee, R.F. Brooks, and R. Wunderlich: Superalloys 2004, The Mineral, Metals and Materials Society, Pittsburgh, 2014, pp. 951-58.

29. D. Szeliga, K. Kubiak, W. Ziaja, R. Cygan, J.S. Suchy, A. Burbelko, W.J. Nowak, and J. Sieniawski: Exp. Heat Fluid Flow, 2017, vol. 87, pp. $149-60$.

30. C.L. Brundidge, J.D. Miller, and T.M. Pollock: Metall. Mater. Trans. A, 2011, vol. 42A, pp. 2723-32.

31. J.D. Miller and T.M. Pollock: Metall. Mater. Trans. A, 2014, vol. $45 \mathrm{~A}$, pp. 411-25.

32. T.J. Fitzgerald and R.F. Singer: Metall. Mater. Trans. A, 1997, vol. 28A, pp. 1377-83.

33. S. Bogner, E. Ivanova, M. Müller, F. Wang, D. Ma, and A. Bührig-Polaczek: Metals, 2015, vol. 5, pp. 1971-83.

34. Y. Li, L. Liu, T. Huang, D. Sun, J. Zhang, and H. Fu: Superalloys 2016, The Mineral, Metals and Materials Society, Pittsburgh, 2016, pp. 293-301.

35. W. Kurz and D.J. Fisher: Acta Metall., 1981, vol. 29, pp. 11-20.

36. L. Li and R.A. Overfelt: J. Mater. Scie., 1997, vol. 37, pp. 3521-32.

37. M. Lamm and R.F. Singer: Metall. Mater. Trans. A, 2007, vol. 38A, pp. 1177-83.

38. M. Montakhab, M. Bacak, and E. Balikci: Metall. Mater. Trans. A., 2016, vol. 47A, pp. 3031-39.

39. M. Konter, E. Kats, and N. Hofman: Superalloys 2000, The Mineral Metals and materials Society, Pittsburgh, 2000, pp. 189200 .

40. M. Hofmeister, M.M. Franke, C. Koerner, and R.F. Singer: Metall. Mater. Trans. B, 2017, vol. 48B, pp. 3132-42.

41. F. Wang, D. Ma, J. Zhang, S. Bogner, and A. Bührig-Polaczek: $J$. Mater. Process. Technol., 2014, vol. 214, pp. 3112-21. 